\title{
An experimental and numerical study of floating breakwaters
}

\author{
Christensen, Erik Damgaard; Bingham, Harry B.; Skou Friis, Andreas Peter; Larsen, Alexander Kruse; \\ Jensen, Karsten Lindegaard
}

\section{Published in:}

Coastal Engineering

Link to article, DOI:

10.1016/j.coastaleng.2018.03.002

Publication date:

2018

Document Version

Peer reviewed version

Link back to DTU Orbit

Citation (APA):

Christensen, E. D., Bingham, H. B., Skou Friis, A. P., Larsen, A. K., \& Jensen, K. L. (2018). An experimental and numerical study of floating breakwaters. Coastal Engineering, 137, 43-58.

https://doi.org/10.1016/j.coastaleng.2018.03.002

\section{General rights}

Copyright and moral rights for the publications made accessible in the public portal are retained by the authors and/or other copyright owners and it is a condition of accessing publications that users recognise and abide by the legal requirements associated with these rights.

- Users may download and print one copy of any publication from the public portal for the purpose of private study or research.

- You may not further distribute the material or use it for any profit-making activity or commercial gain

- You may freely distribute the URL identifying the publication in the public portal 


\section{An experimental and numerical study of 2 floating breakwaters

4 Erik Damgaard Christensen ${ }^{1}$, Harry B. Bingham ${ }^{2}$, Andreas Peter Skou Friis ${ }^{3}$, Alexander Kruse

5 Larsen $^{4}$, and Karsten Lindegaard Jensen ${ }^{5}$ coastal protection. Often the breakwaters are bottom mounted such as rubble mound breakwaters. However, there can be several advantages to use a Floating Breakwater (FB). Therefore, the objective of this paper is to study the effect of two different damping mechanisms of a floating breakwater. Three basic cross-sections of FBs were tested and analysed in 2D; a regular pontoon $(\mathrm{RG})$, a regular pontoon with wing plates attached (WP), and a regular pontoon with wing plates and porous media attached to the sides (WP P100). The damping of the FB motions was due to wave radiation and viscous damping. The viscous damping originated mainly from vortex generation around the edges of the structure and due to energy loss inside the porous material attached to the vertical sides of the floating breakwater. Attaching wing plates to the floating breakwater significantly reduced the motion, which was also anticipated. When the porous sides were attached the motion of the FB increased compared to the (WP) cross-section, but the wave transmission was reduced. The possibility for incorporating the effect of the damping in the radiation/diffraction code WAMIT was assessed. The study showed that the cross section with wing plates reduced the motions of the breakwater to the largest extend, while the cross section with wing plates and porous media attached to the sides reduced the reflection and transmission most effectively.

\footnotetext{
${ }^{1}$ Fluid mechanics, Coastal and Maritime Eng. DTU-MEK, Nils Koppels Alle' 403, 2800 Kgs. Lyngby, Denmark

2 Fluid mechanics, Coastal and Maritime Eng. DTU-MEK, Nils Koppels Alle' 403, 2800 Kgs. Lyngby, Denmark

${ }^{3}$ Present address: Sweco Danmark A/S, Granskoven 8, 2600 Glostrup, Denmark

${ }^{4}$ Present address: COWI, Parallelvej 2 Lyngby, DK-2800 Denmark

${ }^{5}$ NIRAS A/S - Sortemosevej 19 - 3450 Allerød, Denmark
} 


\section{Introduction}

Breakwaters are used to provide sheltered areas for loading and unloading of ships, and for coastal protection. Often the breakwaters are bottom mounted such as rubble mound breakwaters. However, there can be several advantages using a Floating Breakwater (FB). For instance, they can be moved to another location with relatively little effort. When the water depth increases, the costs of a bottom-mounted breakwater increase substantially, which makes the floating breakwater concept economically attractive. Further, if the soil conditions are not suited for high loads, a FB might be the only solution to attenuate the incoming wave field.

The use of FBs can get an enhanced attention in the coming years due to an anticipated development of the ocean space. European oceans will be subject to massive development of marine infrastructure in the near future, see (Christensen et al., 2015). The development includes energy facilities, e.g. offshore wind farms, exploitation of wave energy, and development and implementation of marine aquaculture. This change of infrastructure makes the concept of multi-use offshore platforms (several functionalities in the same area/ or same platform) particularly interesting, where FBs can play an important role in protecting service platforms and offshore terminals.

The single pontoon FB has gained much attention. Most of these studies have been made with the assumption of a very long structure, which allows for analysing the problem in $2 \mathrm{D}$. For instance (Drimer et al., 1992) developed an analytical model for a single pontoon. (Sannasiraj et al., 1998) studied a single pontoon breakwater experimentally and theoretically, (Abul-Azm and Gesraha, 2000) and (Gesraha, 2006) studied the hydrodynamics under oblique waves. (Koutandos et al., 2004) developed a Boussinesq model coupled with a 2DV elliptical model to study the hydrodynamic behaviour of fixed and heave motion FBs. (Rahman et al., 2006) studied the single pontoon breakwater with a VOF-type Navier-Stokes solver (see for instance (Hirt and Nichols, 1981) for the original introduction to VOF-method).

Other types of FBs have also been studied. For instance, (Dong et al., 2008) studied different configurations of partly open breakwaters, i.e. single-box FB, double-box FB, and board-net FB. (Wang and Sun, 2010) examined a porous breakwater where the structure was fabricated with large numbers of diamond-shaped blocks arranged to reduce transmitted wave height and the mooring force. Their results showed that the porous FB reduced transmission of a large part of the incident wave energy through dissipation rather than reflection of the wave energy. (Ji et al., 2015) and (Ji et al., 2016) used experiments to optimize the configuration of FBs. They found that a FB consisting 
of two pontoons with a mesh between them gave the best performance in wave attenuation. Further, they suggested that this could be combined with porous structures in order to improve the functionality of the structure. (Tang et al., 2011) presented another dual pontoon floating structure, where the pontoons supported a fish net for aquaculture. In this case the fish net acts as a very open porous structure, which in (Wang and Sun, 2010) was found to increase the wave attenuation caused by energy dissipation. Examples of full three-dimensional studies of FB can for instance be found in (Loukogeorgaki and Angelides, 2005) and (Loukogeorgaki et al., 2014).

Traditional breakwaters can be divided into reflective, such as vertical wall breakwaters, and dissipative such as rubble mound breakwaters. These two types of breakwaters have been intensively studied and it is out of the scope of this paper to give a further introduction to them. However, (CIRIA et al., 2007; Goda, 2010) give a good introduction to their function and design. The transmission through a vertical breakwater will typical be very small and originates from diffraction and overtopping processes. Diffraction and overtopping processes are also important for rubble mound breakwaters, but rubble mound breakwaters are also subjected to transmission of wave energy depending on the width and height of the structure and, furthermore, on the porous material of the interior. The effect of the porous media on the incoming waves has in recent years gained attention with the use of advanced numerical models as discussed for example by (Garcia et al., 2004; Jacobsen et al., 2015; Jensen et al., 2014; Losada et al., 2005). The single pontoon FB reflects rather than dissipates the wave energy. Compared to the vertical breakwater the transmission of energy is of course much higher as the wave energy is translated under the pontoon and through wave radiation caused by the motion of the breakwater. The wave radiation is often related to the roll motion of the FB, which can be reduced by adding wings or in ship terminology, bilge keels, to the pontoon, which increases the viscous damping. Another way could be active roll control devices, see for instance (Perez and Blanke, 2012). The active roll control devices might be less attractive for a FB as this will lead to a more complex and thus, a more expensive structure. Wings increase wave attenuation by dissipating energy, and a smaller part of the incoming wave energy is transmitted due to reduced wave radiation caused by rolling of the FB.

This paper presents experimental and numerical analyses of the motion of a FB, and its reflection, dissipation and transmission of wave energy. The basic geometry of the cross section of the FB was based on a single pontoon, which was modified in several steps in order to examine the effect of roll damping wings and porous media on the side of the breakwater. Therefore, the objective of this paper is to study the effect of two different damping mechanisms, and how they 
influence the reflection and transmission of waves. Section 2 describes how we measured the motion of the FB with particle tracking techniques as well as with accelerometers in a laboratory wave flume. The surface elevation was measured with wave gauges on the front and lee side of the FB. Section 3 presents the analyses of the measured data, where the response amplitude operator (RAO) and the derived wave characteristics from surface elevations are presented. The set-up of the numerical model is described in section 4 that included an attempt to account for external viscous damping, and to model the mooring system as an external stiffness matrix. The numerical analyses were compared to the experimental results in section 5 .

\section{Experiments with a floating breakwater (FB)}

The objective of this study was to evaluate the effect of two different approaches to reduce the transmission of wave energy to the lee side of a single pontoon FB. Therefore, we evaluated three main cases; a regular pontoon (RG), a pontoon with wings (bilge keels) attached (WP), and a pontoon with wings and porous sidewalls (WP P100).

We use the common notation for the six DOF (degrees of freedom) of which only the sway, heave and roll were studied as sketched in Figure 1. The figure also indicates that a cross-section of the FB was examined in the study.

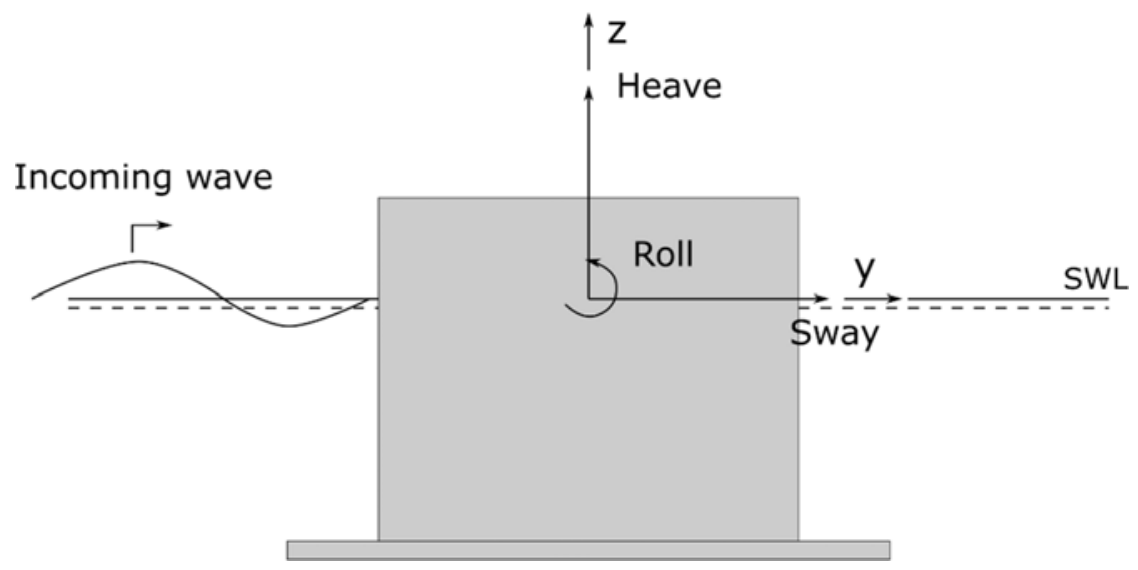

Figure 1 Definition sketch of the DOF (Degrees Of Freedom) that was examined in this study.

The normalized Response Amplitude Operator (RAO) is the ratio of the amplitude of the FB motion to the amplitude of the incoming wave:

$$
R A O_{i}(\omega)=\frac{\xi_{i}}{A}, i=1 \sim 6
$$


115 Where $R A O_{i}$ is the response amplitude operator for motion $\mathrm{i}$, that is a function of frequency $\omega . \xi_{i}$

116 is the amplitude of the $\mathrm{i}^{\text {th }} \mathrm{DOF}$, and $\mathrm{A}$ is the amplitude of the incoming periodic waves.

117 In the experimental and numerical analyses we only analysed the sway, heave and roll, 118 corresponding to $i=2,3,4$. To estimate the response amplitude and the reflection and transmission 119 of waves, the wave elevation at several positions and the motion of the FB were evaluated. The

120 following sub-section describes the wave flume and experimental set-up.

122

123

124

125

126

127

128

129

130

131

132

133

134

135

136

137

138

139

140

\subsection{The wave flume and experimental set-up}

The tests were carried out in a wave flume in the hydraulic laboratory at the Technical University of Denmark. The flume is $28 \mathrm{~m}$ long, $0.6 \mathrm{~m}$ wide, and the sidewalls are $0.8 \mathrm{~m}$ high. The pontoon took up almost the entire width of the wave flume to reduce side effects in the twodimensional experiments.. The distance from the wave piston paddle to the end of the wave absorber was $25 \mathrm{~m}$. The flume was used with waves alone even though it also had the ability to include currents. The sidewalls of the flume consisted of a long range of glass that made it possible to follow the motions of the FB. The flume was equipped with a piston-type wave maker at one end and a wave absorber at the other end. The water depth in the flume was $0.615 \mathrm{~m}$.

\section{Piston type}

wave generator
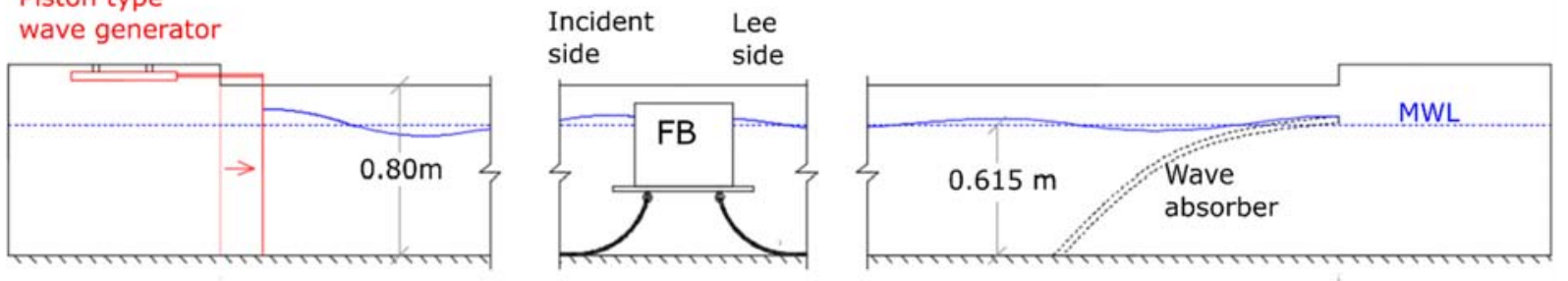

$25 \mathrm{~m}$

Figure 2 Sketch of the wave flume. The sketch is divided into sections to keep proportions.

\subsubsection{Wave measurements and analyses}

One of the major objectives of the experimental set-up was to distinguish between the incident, $\mathrm{H}_{\mathrm{I}}$, reflected, $\mathrm{H}_{\mathrm{R}}$, and transmitted, $\mathrm{H}_{\mathrm{T}}$, wave heights. From the measured wave heights, the reflection and transmission coefficients were defined as:

$C_{R}=H_{R} / H_{I}$

$$
C_{T}=H_{T} / H_{I}
$$



used conventional resistance-type wave gauges in the measurements with a sampling frequency of $120 \mathrm{~Hz}$. The surface elevation on the incident side of the FB was measured with 4 wave gauges while 3 wave gauges covered the lee side surface elevation, see Figure 3.

145

146

147

148

149

150

151

152

153

154

156

157

158

159

160

161

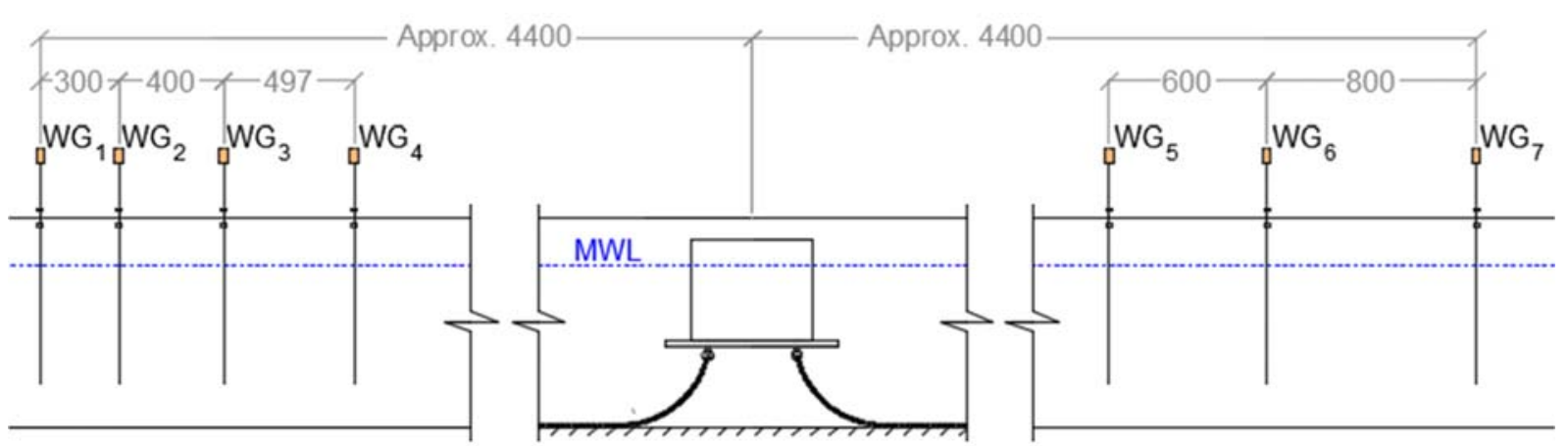

Figure 3 Positions of wave gauges in unit [mm].

The method used in this study to determined incoming and reflected waves was the one presented in (Jacobsen et al., 2012). To separate the incoming and reflected waves an overdetermined set of equations was formed. Equations (2.4), (2.5), and (2.6) refer to a system with two wave gauges:

$$
\eta_{i, 1}=a_{0}+\sum_{j=1}^{N} a_{j}^{I} \cos \left(j\left(\omega t_{i}-k x_{1}\right)\right)+b_{j}^{I} \sin \left(j\left(\omega t_{i}-k x_{1}\right)\right)+
$$

$$
\begin{array}{r}
\sum_{j=1}^{N} a_{j}^{R} \cos \left(j\left(\omega t_{i}-k x_{1}\right)\right)+b_{j}^{R} \sin \left(j\left(\omega t_{i}-k x_{1}\right)\right) \\
\eta_{i, 2}=a_{0}+\sum_{j=1}^{N} a_{j}^{I} \cos \left(j\left(\omega t_{i}-k x_{2}\right)\right)+b_{j}^{I} \sin \left(j\left(\omega t_{i}-k x_{2}\right)\right)+
\end{array}
$$

$$
\sum_{j=1}^{N} a_{j}^{R} \cos \left(j\left(\omega t_{i}-k x_{2}\right)\right)+b_{j}^{R} \sin \left(j\left(\omega t_{i}-k x_{2}\right)\right)
$$

for

$$
t_{i}=t_{0}, t_{0}+\Delta t, \ldots, t_{0}+M \Delta t
$$

$\eta_{i, 1}$ is the surface elevation at wave gauge 1 , at time step i, $a_{j}^{I}$ and $b_{j}^{I}$ are amplitudes in the incoming wave and $a_{j}^{R}$ and $b_{j}^{R}$ in the reflected wave. $x_{1}$ and $x_{2}$ are the positions of wave gauge 1 and wave gauge 2 . The index $\mathrm{j}$ is the number harmonic out of $\mathrm{N}$ harmonics. $\mathrm{k}$ is the wave number 
162 and reflects the assumption that all harmonics are bound. The overdetermined system of equations

163 (2.4) and (2.5) is solved numerically giving the incoming and reflected amplitudes from which

164 reflection coefficients etc. can be determined.

165 The number of harmonics, N, was three in our analyses. However, the difference between

166 using one harmonic instead of three was typically less than a percent on the result on for instance

167 the reflection coefficient, and the difference between using two and three harmonics even smaller.

168 Furthermore, to improve the accuracy the horizontal spacing between each wave gauge was not the

169 same. This prevents e.g. the nodes of a standing wave to coincide with the positions of more than

170 one of the wave gauges, which could lead to an ill-conditioned system of equations resulting in poor 171 accuracy.

172 The wave gauges were calibrated before conducting the experiments by a traditional

173 procedure where a relationship between the measured voltage and the water surface position was

174 established, see (Friis and Larsen, 2015). The data acquisition of the wave gauges began in calm

175 water before the wave maker was started and continued to measure up to approx. $60 \mathrm{~s}$ after the

176 wave maker was stopped. The early beginning and late closure were included in order to measure

177 the increasing/decreasing wave activity for the benefit of the Fast Fourier Transformation of the

178 accelerometer signals, which were stored in the same data file as the wave gauge measurements, cf.

179 section 2.1.3 for a description of the accelerometers.

180

181

\subsubsection{Particle tracking}

182 The motions of the FB model were determined by combining video recordings with the 183 software Particle Tracking, (Pastor, 2007). The camera used was a $50 \mathrm{~Hz}$ High Definition video

184 camera, and it delivered pictures with dimensions of $1920 \times 1080$ pixels. A sketch of the set-up with 185 camera and light sources is given in Figure 4. 


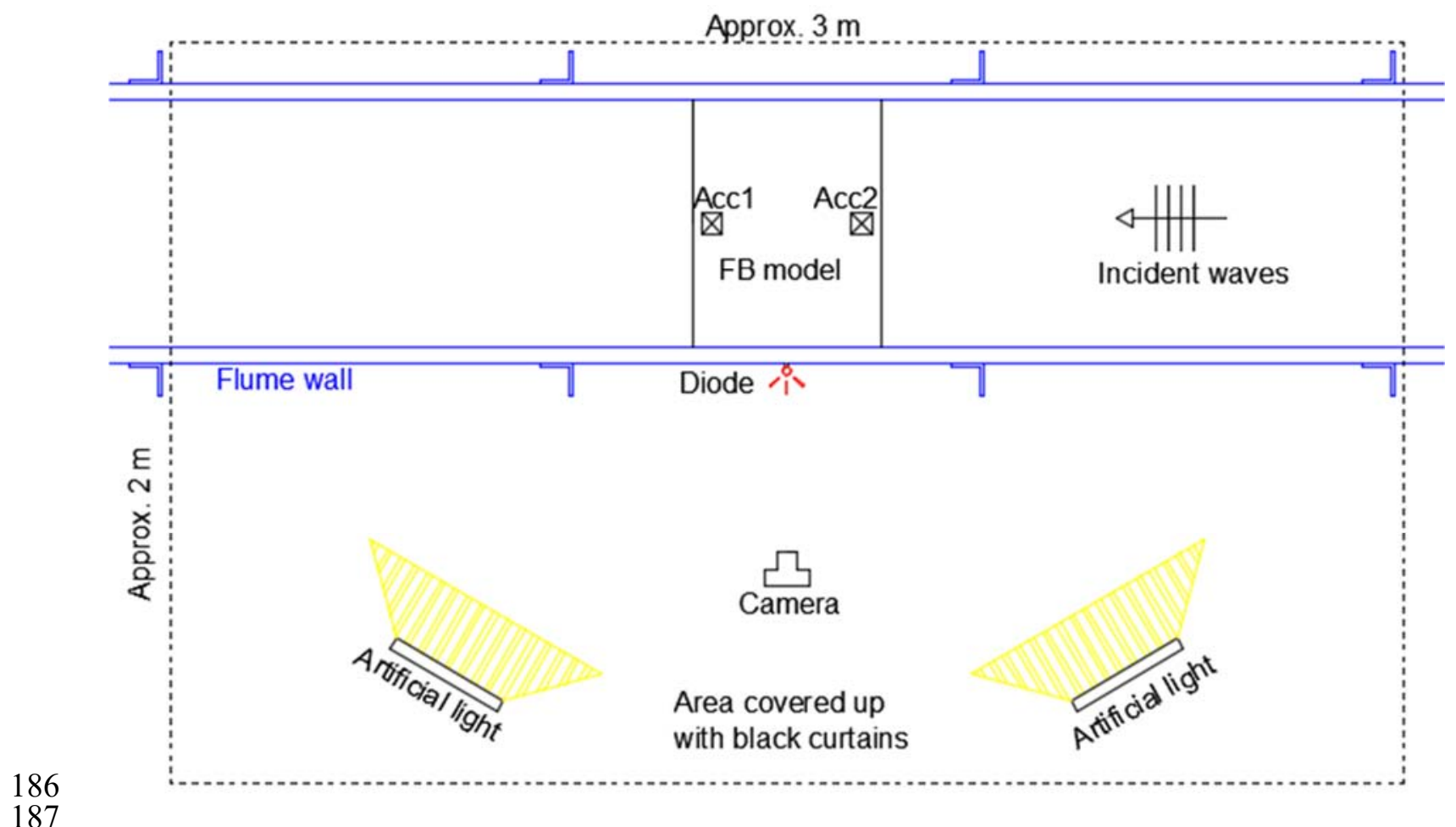

Figure 4 Schematic top-view of the flume with black curtain set-up.

189

190

191 with known individual distances making it possible to measure the distances on the pictures and

192 transform the tracked motions from pixels into meters, see Figure 5. 


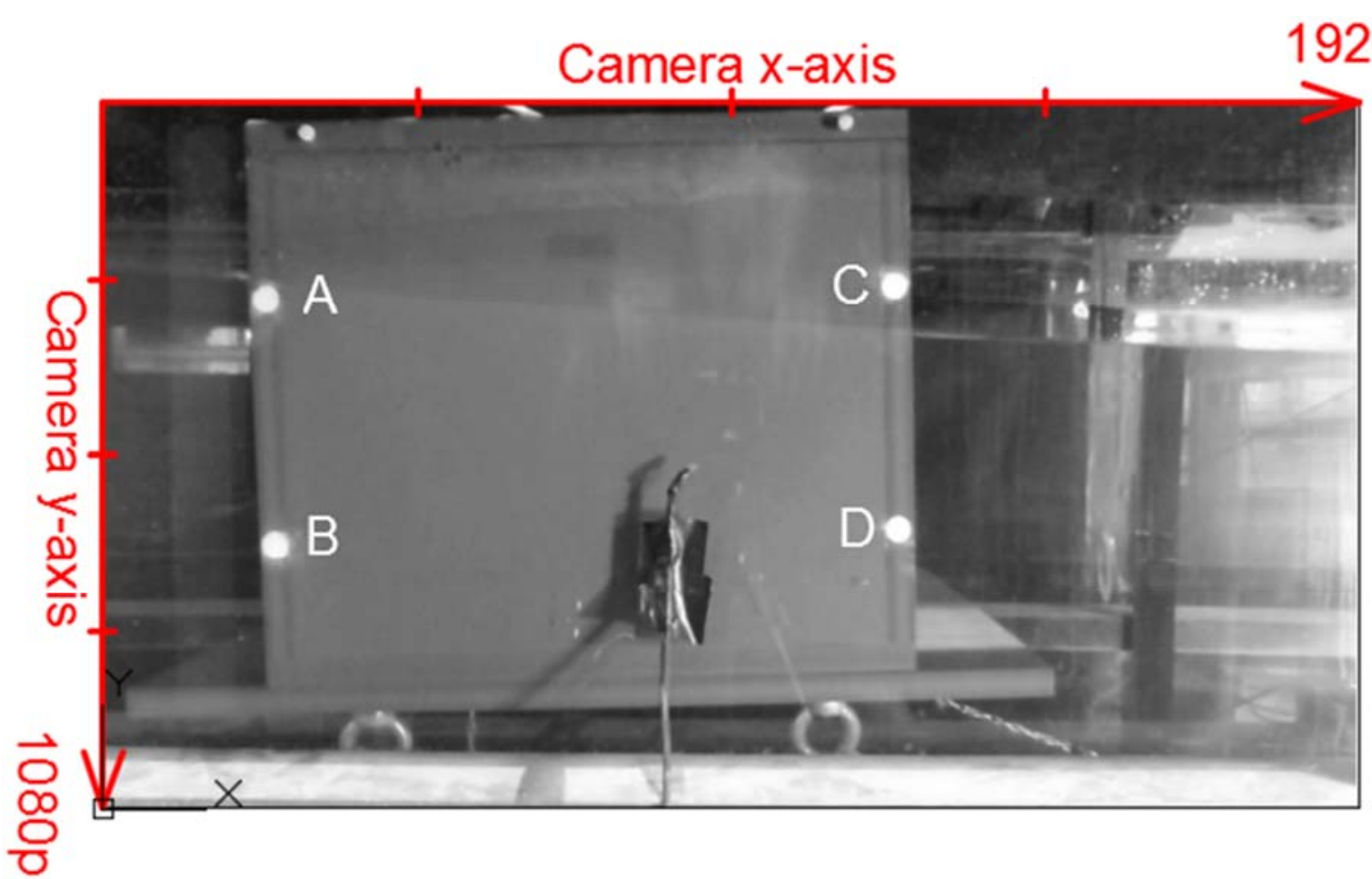

Figure 5 Positions of 4 white points on the side of the floating breakwater (FB) model: $A, B$, $C$, and D.

In order to track the motions of the 4 white spots, they had to be easy to identify to avoid confusion with other white objects in the picture like for instance reflections from blank metal surfaces or sunlight. This was solved by covering up the flume with black curtains and using artificial lights, cf. Figure 4.

\subsubsection{Measuring motions with accelerometers}

As a supplement to the Particle Tracking method described in section 2.1.2, the movements of the FB models were evaluated by accelerometers as well. The reason for this additional measurement was to verify the accuracy of the Particle Tracking method and to examine a suitable alternative, which does not require as much processing of the output. Two 3-axis accelerometers were used to measure the two translational motions and the roll rotation, see Figure 6 . The accelerometers were connected to a power supply and the output was a signal in conditioned voltage stored in the software program DAQ (Data Acquisition). The accelerometers measured the accelerations with full scale range of $\pm 3 \mathrm{~g}$. 

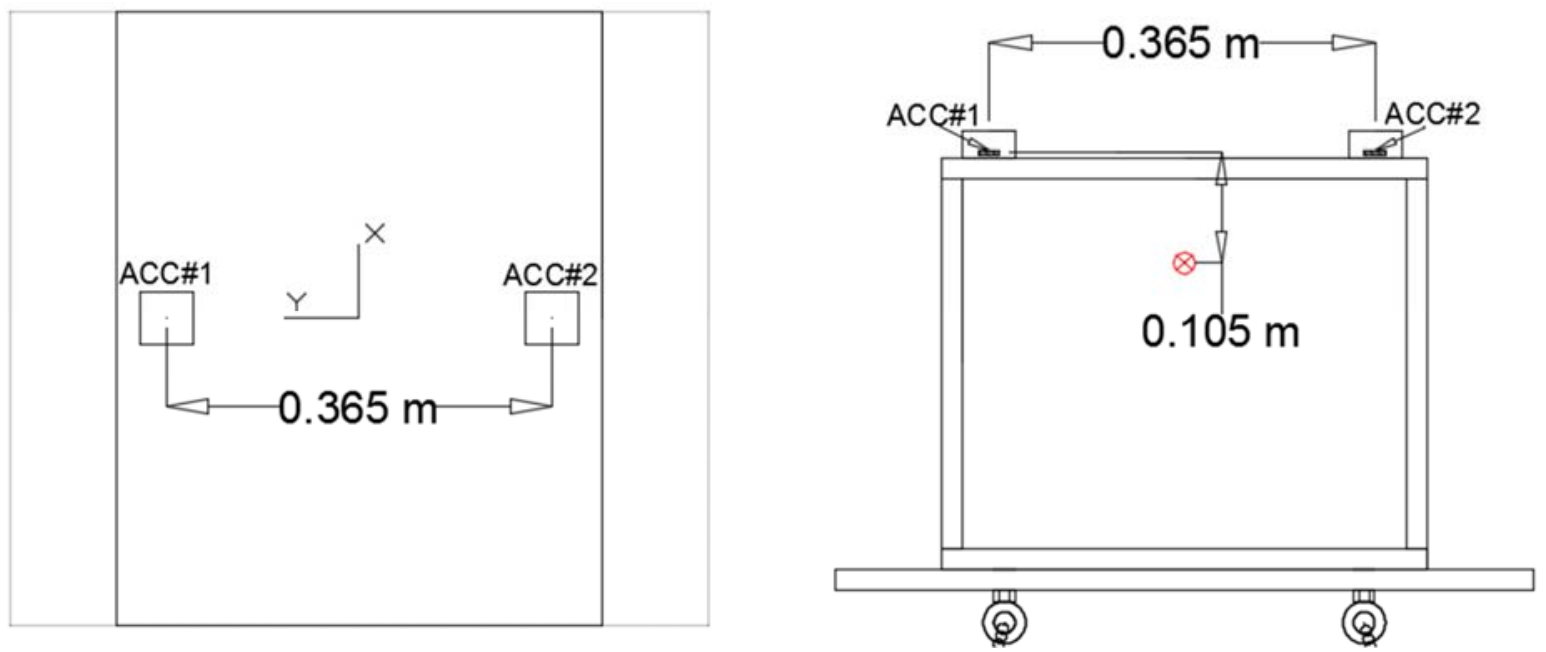

Figure 6 Sketch of the set-up of the accelerometers for the FB model with wings. The vertical distance from the MWL to the lid is indicated on the right panel.

\subsection{Cross-section of the FB}

The physical model tests targeted a two-dimensional situation where cross-sections were tested and analysed in the wave flume. The FB model had to fit into the wave flume and therefore the regular pontoon $(\mathrm{RG})$ cross-section had the dimensions $0.46 \mathrm{~m}$ wide, $0.39 \mathrm{~m}$ high and $0.58 \mathrm{~m}$ long. The height of the other two cross-sections with a wing attached was $0.41 \mathrm{~m}$, and the total width was $0.66 \mathrm{~m}$. The FB was ballasted to give a draft of $0.31 \mathrm{~m}$ that was kept constant for all three cross-sections. With a total water depth of $0.615 \mathrm{~m}$ in the wave flume, the clearance was 0.305 $\mathrm{m}$ between the breakwater and "seabed". Figure 7 illustrates the cross-section of the regular pontoon $(\mathrm{RG})$ with catenary anchor chains attached to the bottom of the pontoon. 


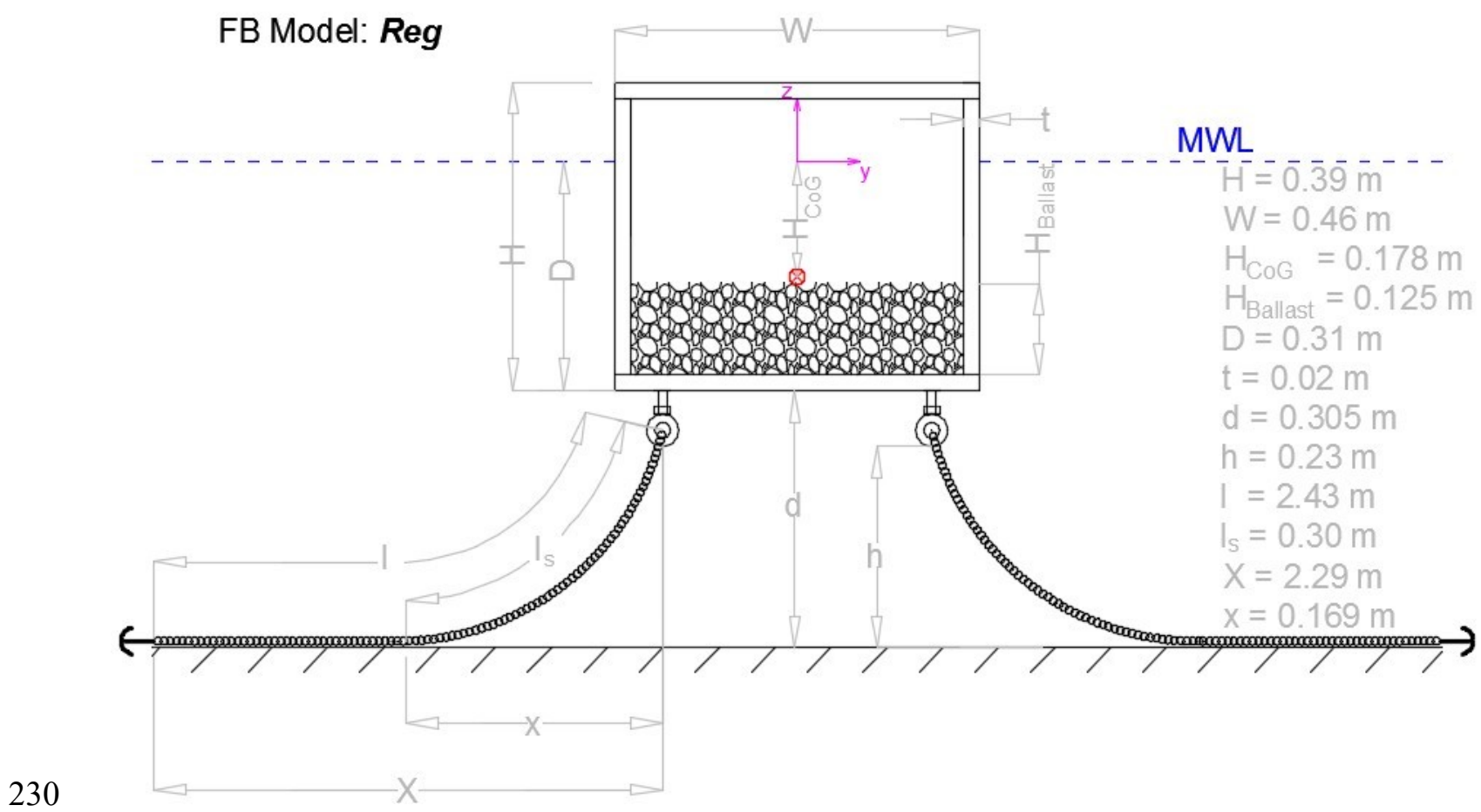

231 Figure $7 \quad$ Basic cross section of the regular pontoon (RG) floating breakwater.

233

234

235
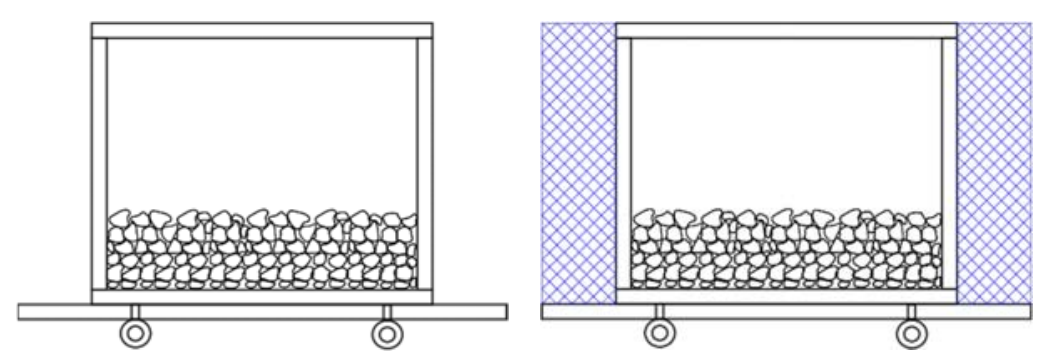

Figure 8 The basic three different types of breakwaters, (RG), (WP), and (WP P100).

The center of gravity, $H_{C O G}$, was $H_{C o G}=0.178 m$ below the still water level for the regular pontoon(RG), $0.176 \mathrm{~m}$ for the pontoon with wings (WP), and $0.175 \mathrm{~m}$ for the pontoon with wings and porous sides (WP P100). Figure 8 shows sketches of the three cross-section.

The porous material was based on filter material normally used for aquariums and made of polyurethane (PU ) foam. The thickness was $10 \mathrm{~cm}$ and the material was relatively coarse with 10 PPI (pores per inch). A photograph of the material is given in Figure 9. 


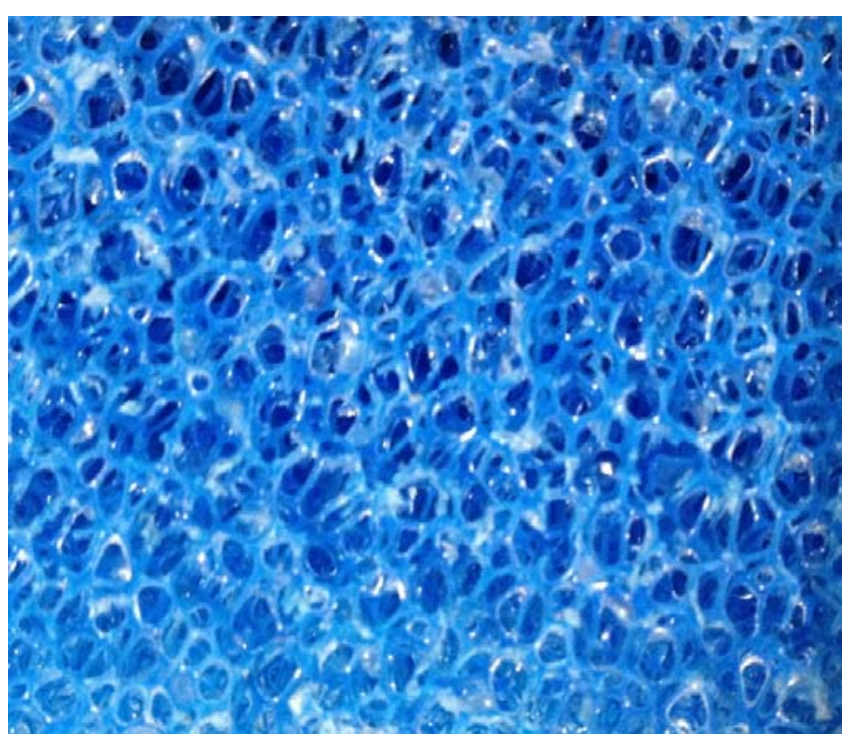

Figure 9 The porous material

\subsubsection{Mooring system}

The design of the mooring system has not been one of the main objectives for this study, as the focus was on the behaviour of the FB and the effect on the reflected and transmitted waves for various damping mechanisms.

Four mooring lines kept the FB in place in the wave flume. The mooring system was designed to be quite soft. The mooring system will therefore only have a small influence on the dynamics in heave and roll, but still be able to fix the average position of the FB in the sway direction. In this way, it mainly counteracted the mean drift forces while it appeared almost freely floating towards wave forces from periodic waves. The mean drift forces were not measured, but the numerical model gave an indication of their size, see for instance Figure 20. The mooring system consisted of four mooring lines, two on each side of the cross-section. The submerged weight of the mooring line was $w=0.589 \mathrm{~N} / \mathrm{m}$. The pretension in the mooring lines for calm water was $T_{\text {pre }}=0.05 \mathrm{~N}$. The total line length was, $l=2.43 \mathrm{~m}$. The total horizontal extent was $X=2.29 \mathrm{~m}$ and the active part was $x=0.17 \mathrm{~m}$. Figure 7 illustrates the cross-section of the mooring system for the (RG) cross-section. The mooring system was set-up in the same way for all three cross-sections.

\subsubsection{Test scenarios}

It is desirable to keep the nonlinearity of the waves generated in the flume at a uniform level over the entire range of frequencies. In deep water, the appropriate measure of nonlinearity is the wave 
steepness, $S=H / L$, which has a maximum value of $S_{\max }=14.2 \%$. However, most of the test

267 scenarios were in the intermediate range from deep to shallow water. This is also a realistic range

268 for the application of FBs. To define a convenient uniformly valid measure for the nonlinearity, we 269 related the wave height to the maximum wave height of progressive stable waves given by the 270 following expression by (Fenton, 1990), which is a fit to the results of (Williams, 1981):

$$
\frac{H_{\max }}{h}=\frac{0.141063 \frac{L}{h}+0.0095721\left(\frac{L}{h}\right)^{2}+0.0077829\left(\frac{L}{h}\right)^{3}}{1+0.0788340 \frac{L}{h}+0.0317567\left(\frac{L}{h}\right)^{2}+0.0093407\left(\frac{L}{h}\right)^{3}}
$$

272

274

275

276

277

278

279

280

281

282

283

284

285

286

287

288

289

290

This limit was then converted to an equivalent deep water steepness, $S_{\text {equiv }}$, defined by:

$$
S_{\text {equiv }}=0.142 \frac{H}{H_{\max }}
$$

where $H$ is the actual wave height used in the tests. The equivalent deep-water steepness $S_{\text {equiv }}$, is then fixed at $2 \%, 3 \%$ and $4 \%$. As could be expected, the results showed a nearly linear increase in the response with increasing equivalent wave steepness over this range, and we therefore focus on the steepness of $2 \%$ in the following.

The test scenarios were based on a first estimate of the design parameters relevant for a depth of $40 \mathrm{~m}$, a draft of $20 \mathrm{~m}$, a peak period of $7 \mathrm{~s}$, and a significant wave height of $2.5 \mathrm{~m}$. This can be considered as moderate waves, but most cargo handling situations need protection from conditions like this. The data were scaled by 1:65 assuming Froude scaling to be valid. Froude scaling was considered valid as long as viscous effects are negligible. This assumption is expected to hold for diffraction forces. However, viscous effects will have an effect in the analyses. The viscous effects from the wings will be scaled correctly as the eddies will detach at approximately the same points in both model- and full-scale. Other viscous effects, such as skin friction and friction in the porous media cannot be assumed to be modelled correctly using Froude scaling. As the focus was on the interaction with waves and transmission of waves we found the Froude scaling as the preferred scaling law. Table 1 shows the conditions tested in the experiments. 
Table 1 Wave parameters for physical model tests in model scale.

\begin{tabular}{|c|c|c|c|c|c|}
\hline No. & $\begin{array}{c}\text { Wave } \\
\text { Length }\end{array}$ & $\begin{array}{c}\text { Wave } \\
\text { Period }\end{array}$ & Frequency & Depth ratio & $\begin{array}{c}\text { Wave } \\
\text { height }\end{array}$ \\
\hline 1 & $L[m]$ & $T[s]$ & $f[H z]$ & $h / L[]$ & $H_{(2 \%)}$ \\
\hline 2 & 1.174 & 0.868 & 1.152 & 0.524 & 0.023 \\
\hline 3 & 1.519 & 0.992 & 1.008 & 0.405 & 0.030 \\
\hline 4 & 2.252 & 1.240 & 0.806 & 0.273 & 0.041 \\
\hline 5 & 2.618 & 1.364 & 0.733 & 0.235 & 0.045 \\
\hline 6 & 2.979 & 1.488 & 0.672 & 0.207 & 0.049 \\
\hline 7 & 3.333 & 1.613 & 0.620 & 0.185 & 0.052 \\
\hline 8 & 3.681 & 1.737 & 0.576 & 0.167 & 0.054 \\
\hline 9 & 4.024 & 1.861 & 0.538 & 0.153 & 0.055 \\
\hline
\end{tabular}

292

293

294

295

296

297

298

299

300

301

302

303

304

305

306

307

308

309

\section{Experimental results}

\subsubsection{Response amplitude operators (RAO) from experiments}

This section presents response amplitude operators derived from the experimental tests for the conditions outlined in Table 1. Two methods, particle tracking (PT) and accelerometers (ACC), tracked the motions of the FB. The sections 2.1.2 and 2.1.3 describe the methodology used. For the sway motion, only (PT) was used. The following figures have a primary axis that shows the frequency, and a secondary axis where $B_{R G} / L$ (bream/wave length) is shown. Note that the secondary axis does not have an equidistant division.

Figure 10, Figure 11, and Figure 12 show that the motion was effectively reduced for the cross section with wings (WP) compared to the regular pontoon (RG). This was expected as the attached wings enhance both wave damping and frictional damping. The cross section with attached porous material (WP P100) showed less reduction of the motion in heave and roll compared to (WP). The smaller reduction of motion from the regular pontoon was in particular clear for the roll motion. The attached porous media reduced the effect of the wings on the roll motion as it apparently reduced the eddy generating mechanism because the surface of the wing plates was covered by the porous media. The reduction of the heave motion was comparable for the (WP) and (WP P100) cross sections, with slightly larger motion reduction for the cross section with 
310 wings alone. The two techniques to measure the motion, particle tracking (PT) and accelerometers 311 (ACC), showed a good agreement. The difference between the two methods was up to around 2-5\% 312 for the heave and roll motions.

313

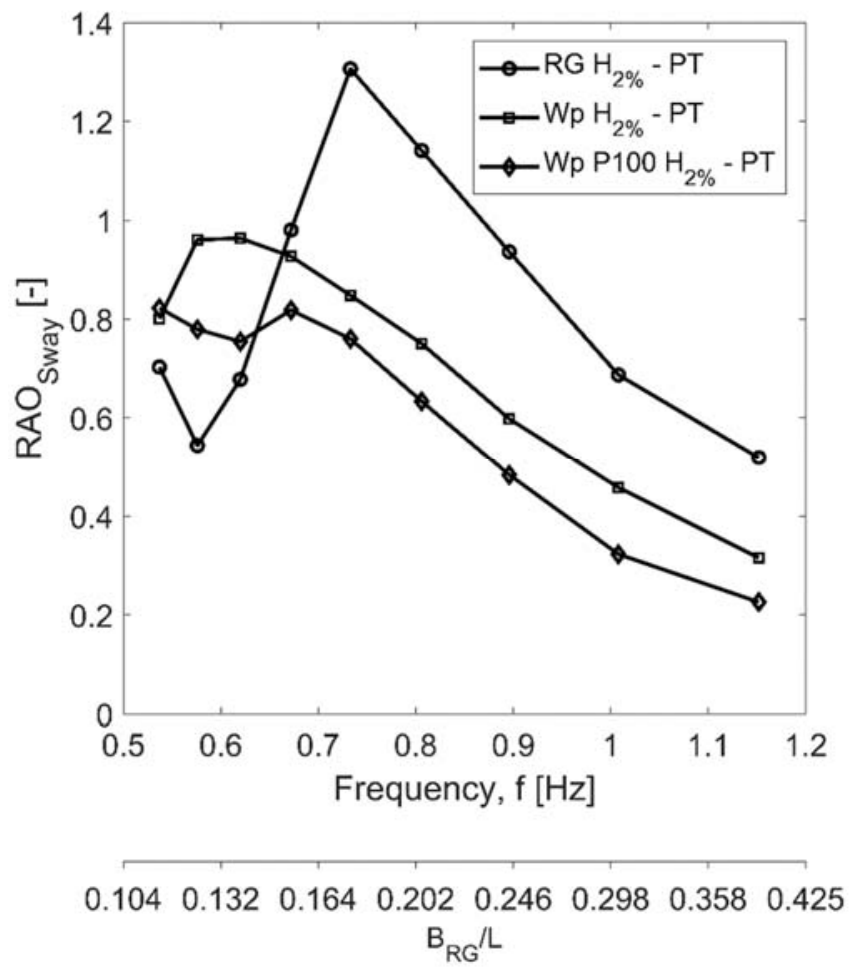

Figure 10 Response amplitude operator (RAO) for Sway derived from experiments for three different cross sections of the FB. 


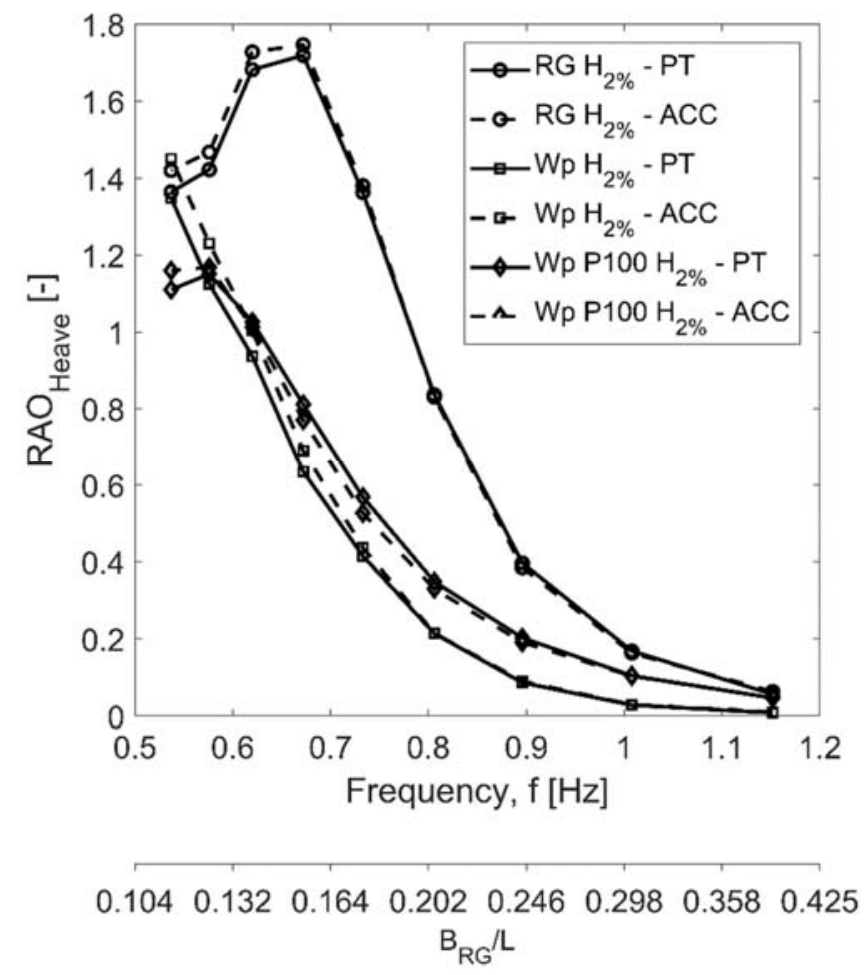

318 Figure 11 Response Amplitude Operators (RAO) Heave derived from experiments for three 319 different cross sections of the FB. 

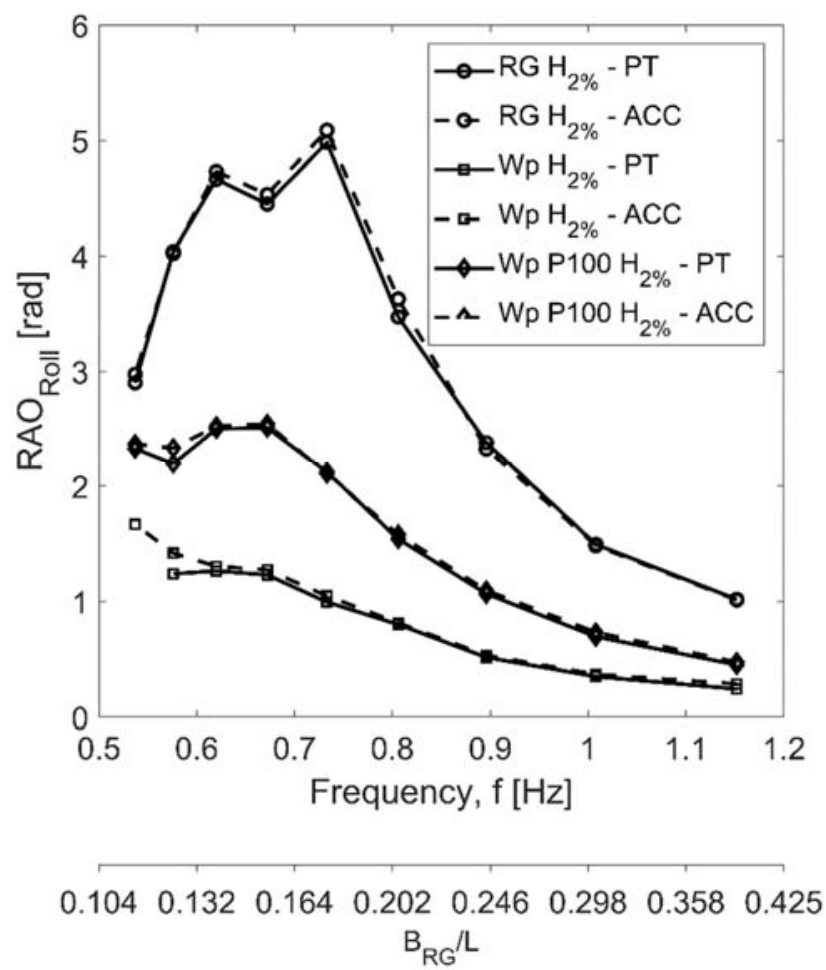

Figure 12 Response Amplitude Operators (RAO) Roll derived from experiments for three different cross sections of the FB.

\subsubsection{Reflection and transmission of wave energy}

The reflection and transmission of wave energy were analysed with standard wave gauges as outlined in section 2.1.1. Figure 13 shows the reflection coefficients, $C_{R}$, as a function of the wave frequency. The maximum reflection coefficient increases towards 0.7 in the area of the analysed frequencies for the regular pontoon (RG) and the pontoon with wings (WP), with an increasing tendency with increasing frequency. It could be argued that for very large frequencies the reflection would go towards $100 \%$ if there are no viscous effects, as the FB would appear as a vertical breakwater with a draft extending to deep water. Even though, including the wings indicated a substantial reduction of motion, this had only minor influence on the size of the reflection coefficient. Actually, the wings increased the reflection coefficient for smaller wave frequencies. When adding the porous media to the sides of the $\mathrm{FB}$, the reflection decreased significantly as the porous media reduced the reflection coefficient from around 0.7 to around 0.3 for the largest wave 
338 frequencies. The picture was not that clear for smaller frequencies as the regular pontoon (RG) gave 339 the lowest reflection.

340

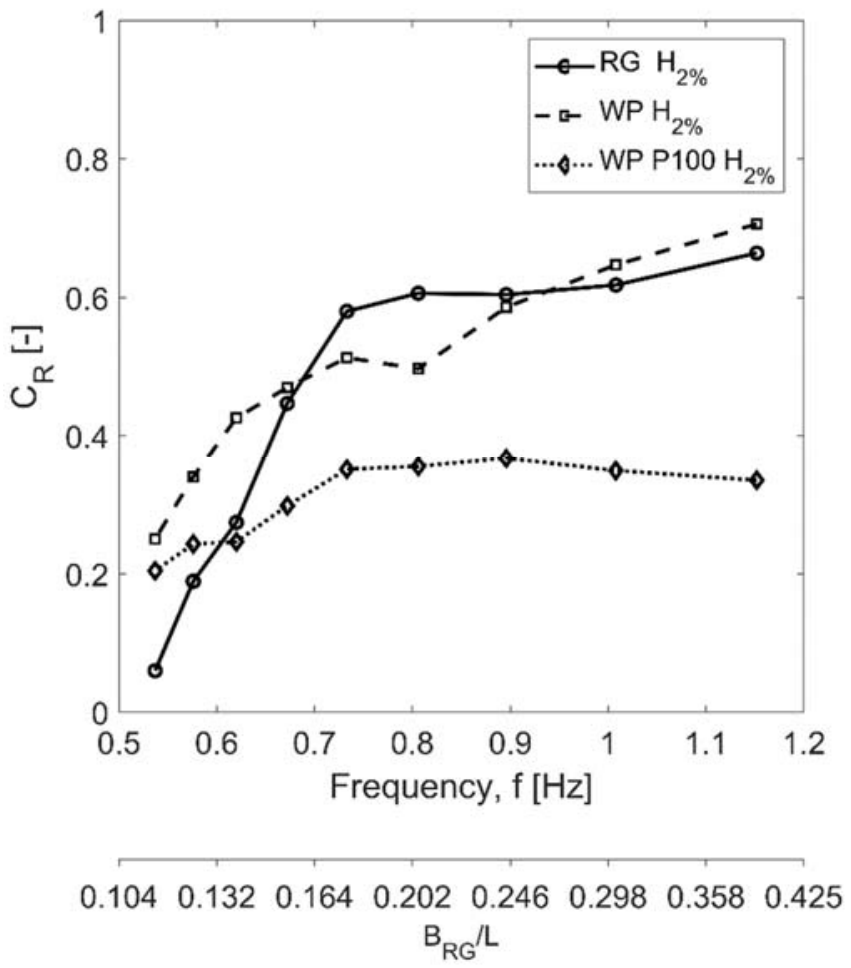

Figure 13 Reflection coefficient, $C_{R}$, for three different cross sections of the FB.

The transmission coefficient, $\mathrm{C}_{\mathrm{T}}$, was smaller for the cross section with porous media compared to the other two cross-sections for larger frequencies, cf. Figure 14. The transmission was similar for large frequencies for the two cross sections (RG) and (WP). The transmission of wave energy was largest for the regular pontoon $(\mathrm{RG})$ for low frequencies. Attaching the porous media to the sides of the FB reduced the transmission coefficient in the order of $50 \%$ for the largest frequencies. For frequencies larger than $0.9 \mathrm{~Hz}$, a decreasing tendency in the transmission with increasing wave frequency was observed for all three cross sections. As wave frequencies increase, the draft of the FB appears deeper preventing transmission of wave energy. At the frequency 0.733 $\mathrm{Hz}$ the $(\mathrm{RG})$ cross section gave a relatively low transmission, which was at the same frequency that gave the maximum RAO for sway and roll. 


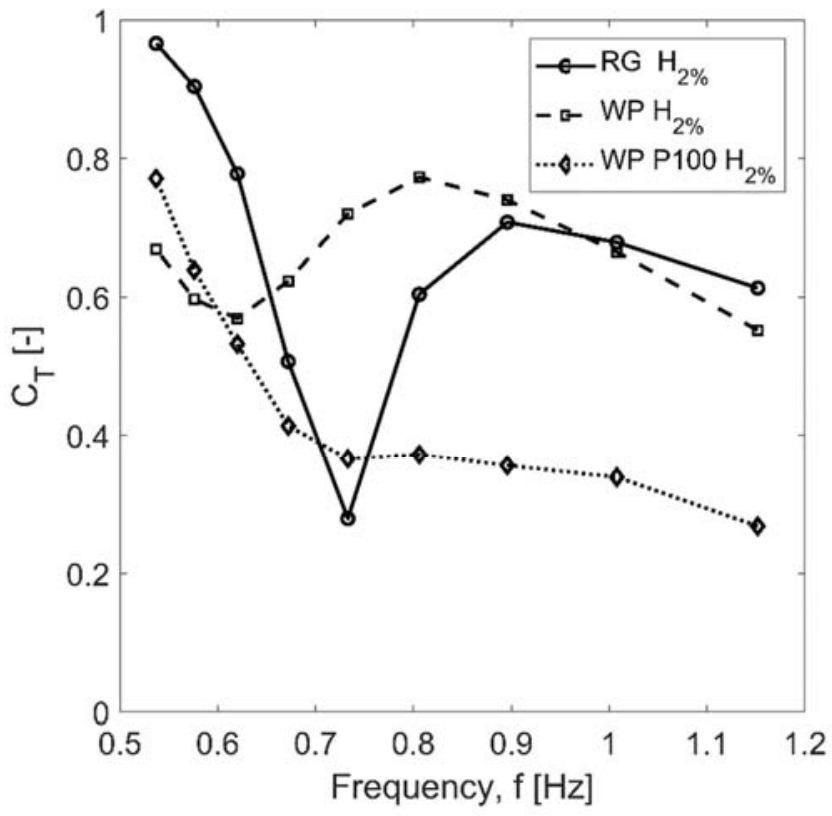

$\begin{array}{llllllll}0.104 & 0.132 & 0.164 & 0.202 & 0.246 & 0.298 & 0.358 & 0.425\end{array}$

355

356

357

358

359

360

361

362

363

364

365

366

367

368

369

370

Figure 14 Transmission coefficient, $C$, for three different cross sections of the FB.

\subsubsection{Wave energy balance}

The total energy balance can be set-up based on $1^{\text {st }}$ order wave theory and gives an indication of the amount of dissipated wave energy. After a transitional period, where a part of the wave energy is used to initiate the movement of the FB, the incoming wave energy will either be reflected, transmitted or dissipated into turbulence and eventually into heat. The reflected and transmitted wave energy were estimated based on analyses of the wave gauge measurements. The dissipated wave energy was not measured directly. Instead, the following relationship was anticipated to be valid:

$$
E_{\text {in }}=E_{R}+E_{T}+E_{\text {diss }}
$$

where $E_{\text {in }}$ is the incoming wave energy, $E_{R}$ and $E_{T}$ are the reflected wave energy and transmitted energy, and finally $E_{D i s s}$ is the amount of energy that eventually is dissipated heat.

Analyses of reflected, transmitted, and dissipated energy are shown in Figure 15, Figure 16, and Figure 17. The transmission of wave energy had a minimum at a frequency of $0.733 \mathrm{~Hz}$ for the regular cross section $(\mathrm{RG})$, cf. Figure 16, which was the frequency where the largest responses were 
371 observed in the RAO for sway and roll. For larger frequencies, the amount of reflected energy was 372 in the same order of magnitude for the regular cross section (RG) and the cross section with wings 373 (WP). The FB will act as a relatively deep vertical solid wall for larger frequencies for the (RG) and 374 (WP) cross sections, and thus, it was expected to reflect a major part of the wave energy for larger 375 frequencies. In our results the width was typically smaller than $1 / 3$ of the wave length, and the draft 376 lower than $1 / 4$ of the wave length, and therefore the structure was too small to reflect the major part 377 of the energy, but the trend with increasing reflection as the frequencies increase (shorter wave 378 lengths) can be seen in the figures. The cross section with the porous media reduced the amount of reflected wave energy. This trend became more pronounced with increasing wave frequency. Similar tendencies were observed for the transmitted wave energy in Figure 16 where the RG and the WP cross sections reduced the transmitted energy. A minimum was observed for the RG cross section, which coincided with the maximum of the RAO for sway and roll. However, in general the cross section with porous media attached to the sides of the breakwater (WP P100) showed the smallest amount of wave transmission. The transmission of wave energy reduced to less than $20 \%$ of the incoming wave energy for frequencies larger than $0.6 \mathrm{~Hz}$.
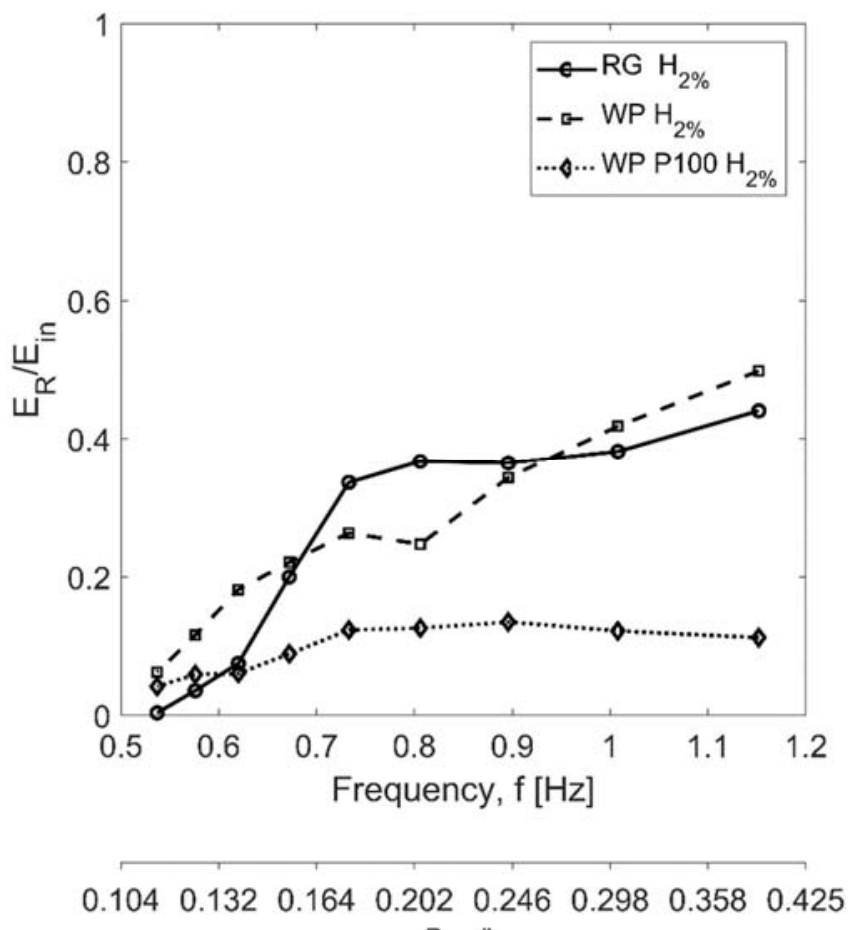


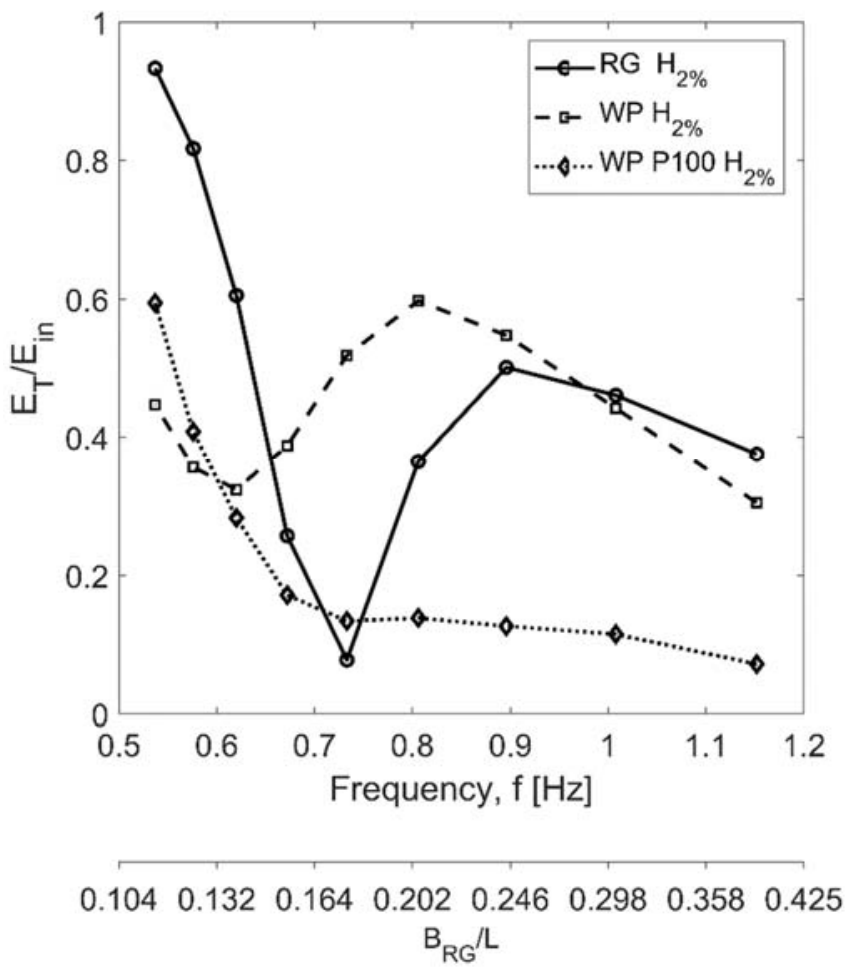

Figure 16 Relative transmission of energy, $E_{T} / E_{\text {in }}$, for three different cross sections of the $F B$.

Figure 17 shows the derived relative dissipation of wave energy. The regular cross section,

$392 \mathrm{RG}$, had its maximum dissipation at the same frequencies for maximum sway and roll motions. The

393 transmitted wave energy was also low at these frequencies. The amount of dissipated energy

394 reached an almost constant level when the porous media was attached to the sides of the FB. From a

395 frequency of around $0.65 \mathrm{~Hz}$, the level of energy dissipation was close to $75 \%$. For the larger

396 frequencies, the increase in dissipated energy was a factor 4-5 times larger than the dissipation rates

397 found for the two other cross sections, (RG) and (WP). 


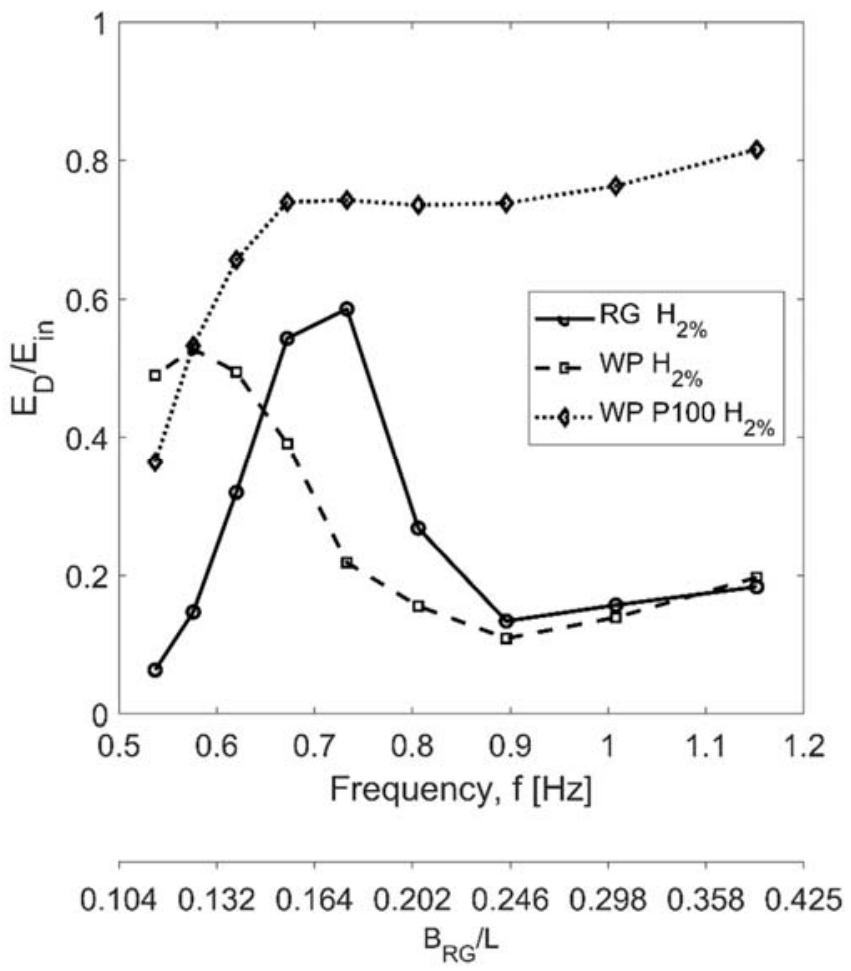

400

Figure 17 Relative dissipation of energy, $E_{\text {Diss }} / E_{\text {in }}$, for three different cross sections of the FB.

402

403

404

405

406

407

408

409

410

\subsection{Decay tests}

Traditionally, the damping force is divided into three types; structural, material and fluid damping, see for instance (Sumer and Fredsøe, 2006). All three types of damping are present during the FB motions, however, the most prominent is the fluid damping, which is subdivided into linear wave damping and viscous damping. Structural damping accounts for external friction in e.g. structure joints while material damping covers the internal friction of a material at the molecular level.

The viscous damping effect is usually determined experimentally based on a decay test. In reality, the viscous damping is not linear, however, an approximate linear damping coefficient will be used in the numerical analyses in the next section.

The ratio $\delta$ between any two amplitudes following each other is constant. Therefore, we can use the logarithmic decrement to find the damping ratio, $\zeta_{j}$. The logarithmic decrement is defined as:

$$
\delta=\ln \left(\frac{x(t)}{x\left(t+T_{d}\right)}\right)=\ln \left(e^{-\zeta_{j} \omega_{n} T_{d}}\right)
$$


417 where $x(t)$ and $x\left(t+T_{d}\right)$ are measured responses at time $t$ and $t+T_{d} . T_{d}$ is the period of damped

418 oscillations and $\omega_{n}$ is the natural angular frequency. While $\zeta_{j}$ is the ratio, which can be computed

419 from:

420

$$
\zeta_{j}=\frac{\delta}{\sqrt{4 \pi^{2}+\delta^{2}}}
$$

421 where $\zeta_{j}$ is proportional to the energy dissipated in one cycle of vibration. 

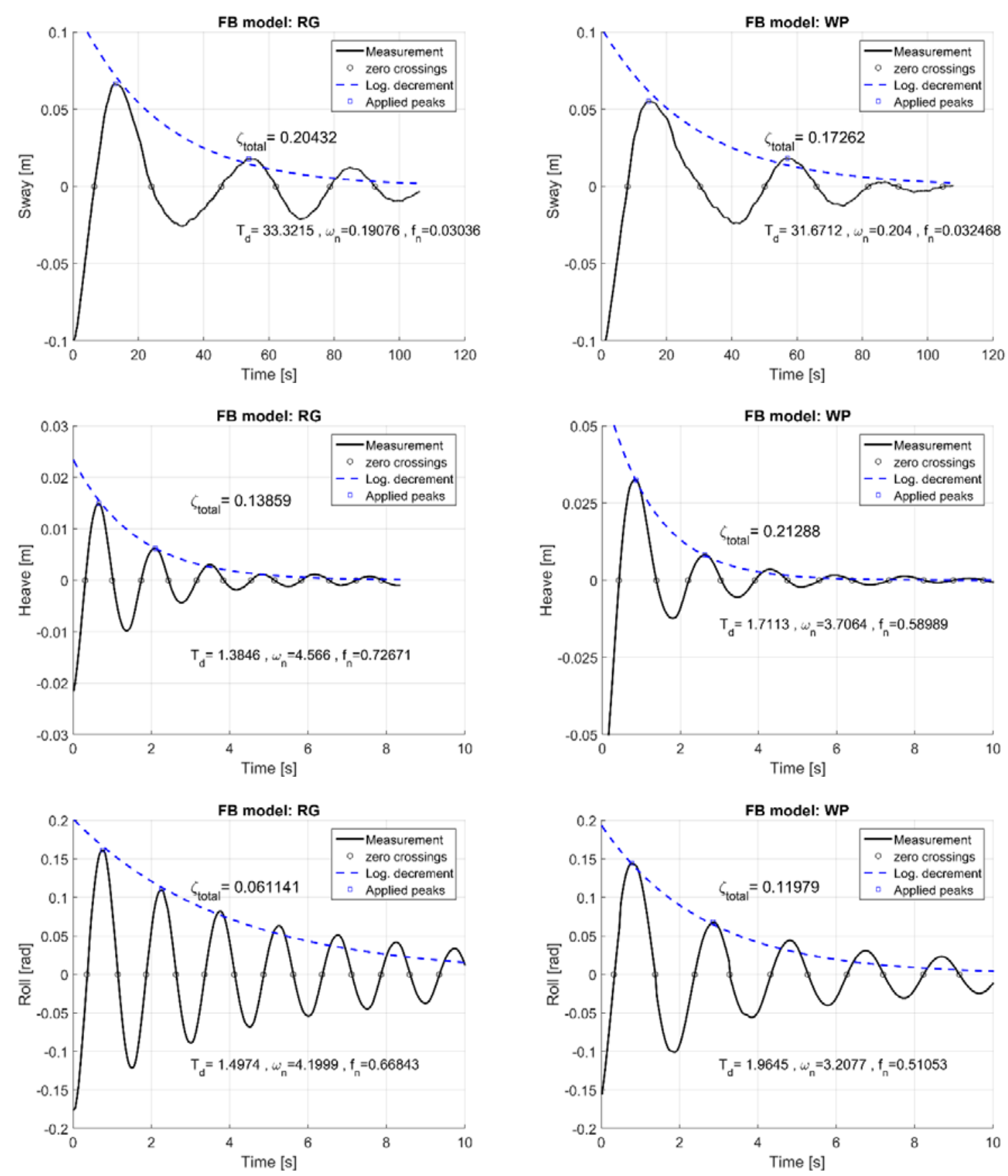

Figure 18 Decay tests for regular and pontoon with wings for sway, roll and heave. 

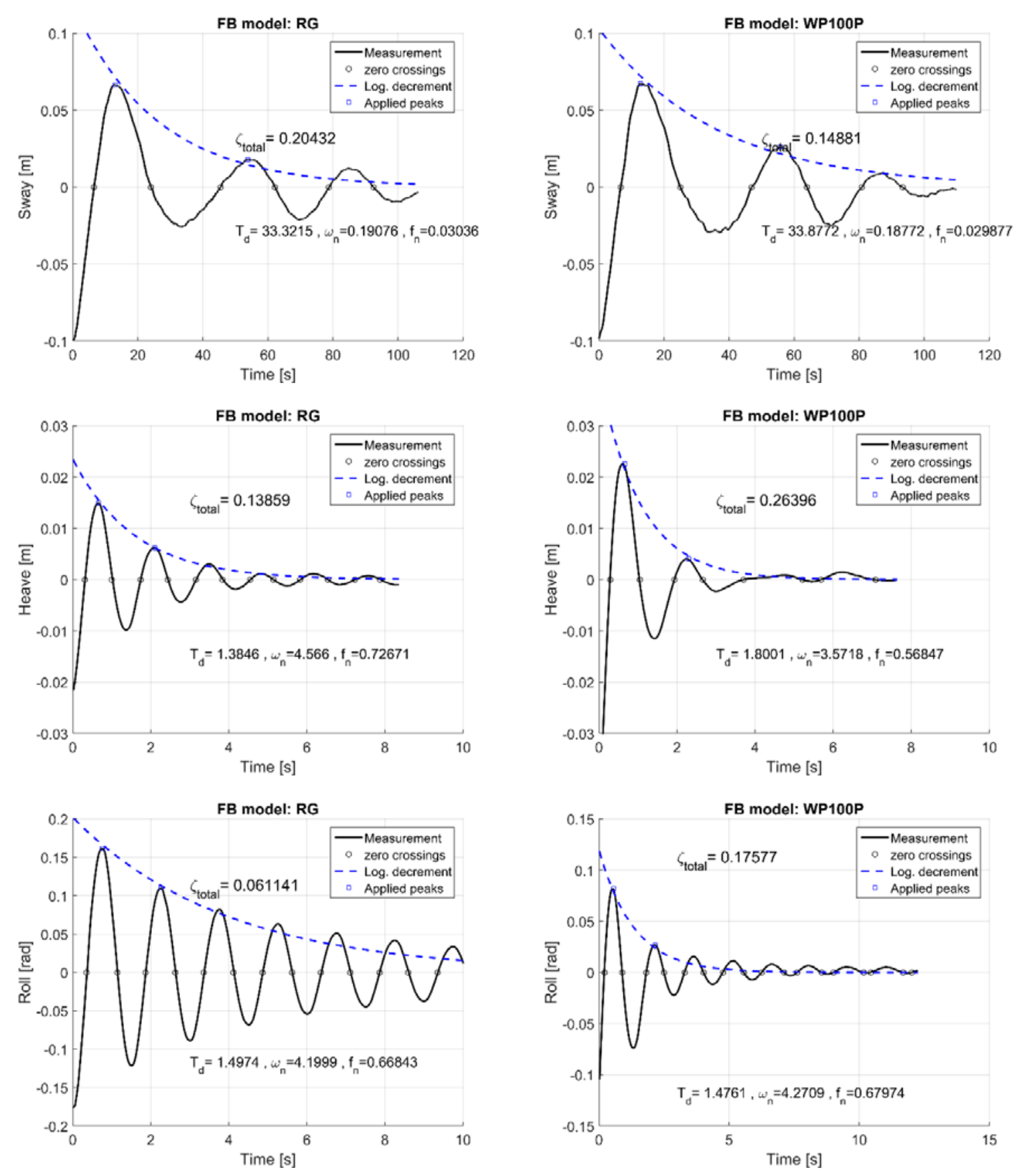

Figure 19 Decay tests for regular and pontoon with wings and porous sides for sway, roll and heave.

430 for frequencies close to the Eigenfrequencies of the system. Figure 18 and Figure 19 show how the 431 damping ratio, $\zeta$, has been estimated from decay tests. Each figure has the regular case (RG) to the 
432 left, while the damping for wings (WP) and porous media (WP P100) is to the right. The sway

433 damping appeared largest for the regular $(R G)$ cross-section. For heave, the (RG) cross section had

434 the smallest damping ratio while the other two cases had higher damping ratios. The case that

435 included porous sides (WP P100) had the largest damping ratio in heave, which might be related to

436 water filling and emptying the porous media. For the roll motion the (RG) cross section had the

437 smallest damping ratio, while the other two cases appeared to be of same order.

438

439

440

441

442

443

444

445

446

447

448

449

450

451

452

453

454

455

456

457

458

459

\section{Numerical modelling}

The exciting force results in dynamical motion of the FB, which for a rigid body can be described in six degrees of freedom (DOF). However, in our case we analysed only the motion in three DOF in order to be able to make comparison with the experimental results. Under the assumption of linearity, and that the exiting force is sinusoidal, the frequency-domain equations of motion can be written, (see for instance (Newman, 1977) ):

$$
\sum_{j=1}^{6}\left[-\omega^{2}\left(M_{i j}+M_{i j}^{E}+A_{i j}\right)+i \omega\left(B_{i j}+B_{i j}^{E}\right)+\left(C_{i j}+C_{i j}^{E}\right)\right] \tilde{\xi}_{j}=\tilde{X}_{i}
$$

where $M_{i j}$ and $M_{i j}^{E}$ are the inertia matrices, $A_{i j}$ is the added mass matrix, $B_{i j}$ and $B_{i j}^{E}$ are damping matrices, $C_{i j}$ and $C_{i j}^{E}$ are the stiffness matrices, $\tilde{\xi}_{j}$ is the complex amplitude of the motion in 6 DOF, and $\tilde{X}_{i}$ is the complex exciting force. External contributions are shown with superscript E. For instance, the anchor chain contributes to the stiffness through the term $C_{i j}^{E}$.

A complex exponential function describes the time-domain motion as follows:

$$
\xi_{j}(t)=\operatorname{Re}\left(\tilde{\xi}_{j} \cdot e^{i \omega t}\right)
$$

where $\xi_{j}(t)$ is the periodic motion in $6 \mathrm{DOF}$, and $\omega$ is the angular frequency of the motion. In the same way, the excitation force can be described as:

$$
F_{i}(t)=\operatorname{Re}\left(\tilde{X}_{i} e^{i \omega t}\right)
$$

where $\tilde{X}_{i}$ is the complex amplitude of the exciting force.

Eqs. (4.1) does not account for non-linear behaviour of for instance damping or non-linear stiffness. However, to include the effect of the non-linear viscous damping, we will estimate an equivalent linear damping as described in section 4.1 based on decay tests in section 3.2. An approximation to the external stiffness matrix, $C_{i j}^{E}$, is given in section 4.2. The Response 
460

Amplitude Operator (RAO) is the ratio of the amplitude of the FB motion to the amplitude of the incoming wave:

$$
\bar{\xi}_{i}=\left|\frac{\tilde{\xi}_{i}}{A}\right|, i=1 \sim 6
$$

An estimate of the single degree of freedom resonant or natural frequency of the FB motion can be found from the following expression that has been used successfully in earlier studies:

$$
\omega_{n i}=\left(\frac{C_{i i}+C_{i i}^{E}}{M_{i i}+A_{i i}\left(\omega=\omega_{n i}\right)}\right)^{\frac{1}{2}}
$$

The index, $i$, refers to the $i^{\text {th }}$ DOF. This study examined the $i=2,3$ and 4 modes.

The solution to the diffraction problem and the equation of motions up to $1^{\text {st }}$ order can be found with the panel method (WAMIT Inc., 2015). WAMIT is a radiation/diffraction panel program developed for linear analyses of the interaction of surface waves with offshore structures. The method is based on potential flow wave theory. The panel method, also referred to as the boundary integral equation method (BIEM), is based on Green's theorem where the velocity potential at any point in the fluid is represented by surface distributions of singularities over the fluid boundary surfaces (Lee and Newman, 2003). The method is used to solve the diffraction and radiation problem describing the interaction between the waves and the floating body.

The numerical modelling was carried out with WAMIT version 7. In this study we used the higher-order method, where Green's velocity potential integrals over the body surface and computational domains are carried out using Gauss quadrature in parametric space, (Lee and Newman, 2003).

The intension of the study was to find the effect of a cross-section of the FB. This was achieved with the sidewalls in the experiments, while this was not possible in the numerical analyses. Instead, the length of the breakwater was set sufficiently large to minimise the 3D effects around the ends of the breakwater. In the x-direction (surge, the length was set to $70 \mathrm{~m}$, while the dimensions in y- (sway) and z-direction (heave) were $0.31 \mathrm{~m}$ and $0.46 \mathrm{~m}$, respectively. The dimensions in the $\mathrm{y}$ and $\mathrm{z}$ directions varied slightly for the three different cross sections as sketched in Figure 8. As the porous media cannot be modelled, a rigid geometry was used that had a total width of $0.66 \mathrm{~m}$ as an approximation for cross-section (WP P100).

The laboratory data was scaled according to the difference between the length in the experiments $(0.58 \mathrm{~m})$ and the length in the numerical analyses $(70 \mathrm{~m})$. For instance the mass was scaled with a factor $70 / 0.58=120.7$, external stiffness coefficients and external damping coefficients 
490

491

492

493

494

495

496

497

498

499

500

501

502

503

504

505

506

507

was also scaled with this factor. No attempt was made to account for three-dimensional effects induced by the ends of the structure.

\subsection{Assessment of external damping}

In the numerical set-up it was possible to include a linear external damping coefficient as a supplement to the wave damping. In general, the viscous damping is a nonlinear process, and cannot be fully represented in the linear numerical analysis. However, an attempt was made to find a realistic representation of the viscous damping from the decay tests that were presented in section 3.

The actual damping coefficient is written as:

$$
B_{i j}=\zeta_{j} B_{c r, i j}=\zeta_{j} 2 \sqrt{\left(M_{i j}+A_{i j}\right) C_{i j}}
$$

where $B_{c r, i j}$ is the critical damping coefficient, known as the smallest value of damping rate that yields non-oscillatory motion:

$$
B_{c r, i j}=2 \sqrt{\left(M_{i j}+A_{i j}\right) C_{i j}}
$$

The natural frequency, $f_{n}$, is calculated once the period $T_{d}$ is identified from a decay test. $T_{d}$ being the period of a damped free oscillation related to the angular damped frequency as $\omega_{d}=\frac{2 \pi}{T_{d}}$.

While the connection to the angular frequency is defined as:

$$
\omega_{d}=\omega_{n} \sqrt{1-\zeta^{2}} \Leftrightarrow \omega_{n}=\frac{\omega_{d}}{\sqrt{1-\zeta^{2}}}
$$

and the frequency in $[\mathrm{Hz}]$ is found as:

$$
f_{n}=\frac{\omega_{n}}{2 \pi}
$$

The natural frequency for each DOF is an important parameter since the FB is affected by periodic external wave forces. Hence, it is important to examine possible coincidence of wave frequencies and FB natural frequencies due to the risk of resonance and thus amplification of the oscillating amplitudes.

The damping ratio originating from viscous damping can be difficult to compare directly between cross sections, as the restoring coefficients also changed between the cross sections, as a consequence of the volume of porous media, and due to different non-linear processes. The numerical model finds the wave damping as a part of the solution. Therefore, we only had to add 
518 the extra damping originating from viscous processes. As the experiments found the total damping 519 coefficient we subtracted the wave damping coefficient found by the calculations from the one 520 found though the experiments. Finally, the additional damping coefficients were adjusted to the 521 length of the FB in the numerical analyses that was $70 \mathrm{~m}$ compared to the $0.58 \mathrm{~m}$ in the 522 experiments. The equations used to find the damping coefficients are presented in eqs. (3.3), (4.6), 523 and (4.7). The tables, Table 2, Table 3 and Table 4, present the relevant damping parameters from 524 the decay tests and numerical modelling. The damping ratio, $\zeta_{\text {total }}$, was found from decay tests, $525 \zeta_{\text {WAMIT }}$ was the damping ratio estimated from the numerical modelling without introducing external 526 damping. The difference between $\zeta_{\text {total }}$ and $\zeta_{\text {WAMIT }}$ was assumed to be the viscous damping;

$527 \zeta_{\text {viscous }}=\zeta_{\text {total }}-\zeta_{\text {WAMIT }}$, and was added as external damping in the numerical analyses. The external 528 damping coefficient, $B_{\text {viscous }}$ was found for each degree of freedom, i.e. sway, heave and roll. Note 529 that mass, added mass, and restoring coefficients varied from cross section to cross section, which 530 means that the damping ratio scales differently depending on the cross section, (RG), (WP), or (WP 531 P100). 
Table 2 Sway decay test results.

\begin{tabular}{|l|l|c|c|c|c|c|c|}
\hline FB model & \multicolumn{1}{|c|}{$\begin{array}{c}T_{d} \\
{[\mathrm{~s}]}\end{array}$} & $\begin{array}{c}\omega_{n} \\
{[\mathrm{rad} / \mathrm{s}]}\end{array}$ & $\begin{array}{c}f_{n} \\
{[\mathrm{~Hz}]}\end{array}$ & $\begin{array}{c}\zeta_{\text {total }} \\
{[-]}\end{array}$ & $\begin{array}{c}\zeta_{\text {WAMIT }} \\
{[-]}\end{array}$ & $\begin{array}{c}\zeta_{\text {viscous }} \\
{[-]}\end{array}$ & $\begin{array}{c}B_{\text {viscous }} \\
{[\mathrm{kg} / \mathrm{s}]}\end{array}$ \\
\hline RG & 33.3 & 0.191 & 0.0300 & 0.204 & 0.0119 & 0.192 & 2393 \\
\hline WP & 31.7 & 0.204 & 0.0325 & 0.173 & 0.0170 & 0.156 & 2725 \\
\hline WP P100 & 33.9 & 0.188 & 0.0299 & 0.149 & 0.0170 & 0.132 & 2234 \\
\hline
\end{tabular}

534

535

536

537

Table 4 Roll decay test results.

\begin{tabular}{|l|c|c|c|c|c|c|c|}
\hline FB model & $\begin{array}{c}T_{d} \\
{[\mathrm{~s}]}\end{array}$ & $\begin{array}{c}\omega_{n} \\
{[\mathrm{rad} / \mathrm{s}]}\end{array}$ & $\begin{array}{c}f_{n} \\
{[\mathrm{~Hz}]}\end{array}$ & $\begin{array}{c}\zeta_{\text {total }} \\
{[-]}\end{array}$ & $\begin{array}{c}\zeta_{\text {WAMIT }} \\
{[-]}\end{array}$ & $\begin{array}{c}\zeta_{\text {viscous }} \\
{[-]}\end{array}$ & $\begin{array}{c}B_{\text {viscous }} \\
{\left[\mathrm{kg} / \mathrm{s} \cdot \mathrm{m}^{2}\right]}\end{array}$ \\
\hline RG & 1.50 & 4.20 & 0.668 & 0.061 & 0.0234 & 0.037 & 193 \\
\hline WP & 1.96 & 3.21 & 0.511 & 0.120 & 0.0074 & 0.113 & 855 \\
\hline WP P100 & 1.48 & 4.27 & 0.680 & 0.176 & 0.0074 & 0.169 & 1340 \\
\hline
\end{tabular}

538

\subsection{A mooring system modelled as an external stiffness matrix} 542 the gradient matrix were described as:

Table 3 Heave decay test results.

\begin{tabular}{|l|c|c|c|c|c|c|c|}
\hline FB model & $\begin{array}{c}T_{d} \\
{[\mathrm{~s}]}\end{array}$ & $\begin{array}{c}\omega_{n} \\
{[\mathrm{rad} / \mathrm{s}]}\end{array}$ & $\begin{array}{c}f_{n} \\
{[\mathrm{~Hz}]}\end{array}$ & $\begin{array}{c}\zeta_{\text {total }} \\
{[-]}\end{array}$ & $\begin{array}{c}\zeta_{\text {WAMIT }} \\
{[-]}\end{array}$ & $\begin{array}{c}\zeta_{\text {viscous }} \\
{[-]}\end{array}$ & $\begin{array}{c}B_{\text {viscous }} \\
{[\mathrm{kg} / \mathrm{s}]}\end{array}$ \\
\hline RG & 1.38 & 4.57 & 0.727 & 0.138 & 0.113 & 0.025 & $3.7 \cdot 10^{3}$ \\
\hline WP & 1.71 & 3.71 & 0.590 & 0.213 & 0.0872 & 0.126 & 22850 \\
\hline WP P100 & 1.71 & 3.77 & 0.600 & 0.264 & 0.0872 & 0.177 & 32443 \\
\hline
\end{tabular}

\section{The external restoring matrix, $C_{i j}^{E}$, was formulated with a general full three dimensional \\ 541 description. For each mooring component the mooring force at an attachment point and especially

$$
\text { description. For each mooring component the mooring force at an attachment point and especially }
$$

\section{.}

$$
\vec{T}=\left(T_{x_{1}}, T_{x_{2}}, T_{x_{3}}\right)
$$$$
T_{k l}=\left[\begin{array}{lll}
\frac{\partial T_{x_{1}}}{\partial x_{1}} & \frac{\partial T_{x_{1}}}{\partial x_{2}} & \frac{\partial T_{x_{1}}}{\partial x_{3}} \\
\frac{\partial T_{x_{2}}}{\partial x_{1}} & \frac{\partial T_{x_{2}}}{\partial x_{2}} & \frac{\partial T_{x_{2}}}{\partial x_{3}} \\
\frac{\partial T_{x_{3}}}{\partial x_{1}} & \frac{\partial T_{x_{3}}}{\partial x_{2}} & \frac{\partial T_{x_{3}}}{\partial x_{3}}
\end{array}\right]
$$ 
545 Where $T_{x 1}$ is the force in the $x$-direction (surge), $T_{x 2}$ is the force in the $y$-direction (sway), and $T_{x 3}$ is

546 the force in the z-direction (heave). $T_{k l}$ is the Jacobian matrix of the vector $\vec{T}, k$ and $l$ are $1,2,3$

547 corresponding to the three spatial coordinates. In our study the forces in the x-direction could be

548 assumed to be zero, however, for the sake of completeness the derivation of the external stiffness

549 matrix included all three dimensions. The derivatives in the Jacobian matrix, $T_{k l}$, eqs. (4.11), were

550 estimated by eqs. (4.21)-(4.24) that are presented later.

551 The restoring forces and moments, $\Delta F_{k}^{n}$ and $\Delta M_{k}^{n}$, from attachment point number $n$ can under

552 the assumption of small motions be found as (all higher order terms are neglected):

553

$$
\left[\begin{array}{c}
\Delta F_{k}^{n} \\
\Delta M_{k}^{n}
\end{array}\right]=\left[\begin{array}{c}
T_{k l}^{n} \cdot u_{l}^{n} \\
R_{k m}^{n} T_{m l}^{n} \cdot u_{l}^{n}
\end{array}\right]
$$

554

555

556

557

558

559

560

561

562

563

564

565

566 567

Here $u_{l}^{n}$ is the displacement of attachment point $\mathrm{n}$ from a mean position. With reference to a coordinate system following the FB, the distance vector from origo to the attachment point was $r_{j}$.

Note that only $1^{\text {st }}$ order terms were included in the derivation. The restoring moment, $\Delta M_{k}^{n}$, can be found as the cross-product between the distance vector, $r_{j}$, and the restoring force, $\Delta F_{k}^{n}$, at the attachment point. However, it was found convenient to formulate the cross-product as a matrix multiplication with $R_{k l}$. Based on the distance vector, $r_{j}$, the formulation of $R_{k l}$ is:

$$
R_{k l}=\left[\begin{array}{ccc}
0 & -r_{3} & r_{2} \\
r_{3} & 0 & -r_{1} \\
-r_{2} & r_{1} & 0
\end{array}\right]
$$

The translation $u_{l}$ of the attachment point in three dimensions can be related to the motion of the FB, $\xi_{j}$, as, $u_{l}=A_{l j} \xi_{j}$. Based on geometrical considerations the matrix $A_{l j}$ were formulated:

$$
A_{l j}=\left[E_{k l},-R_{k l}\right]=\left[\begin{array}{cccccc}
1 & 0 & 0 & 0 & r_{3} & -r_{2} \\
0 & 1 & 0 & -r_{3} & 0 & r_{1} \\
0 & 0 & 1 & r_{2} & -r_{1} & 0
\end{array}\right]
$$

Eqs. (4.12) was rewritten as:

$$
\left[\begin{array}{c}
\Delta F_{k}^{n} \\
\Delta M_{k}^{n}
\end{array}\right]=\left[\begin{array}{c}
T_{k l}^{n} A_{l j}^{n} \\
R_{k m}^{n} T_{m l}^{n} A_{l j}^{n}
\end{array}\right] \xi_{j}
$$

Based on eqs. (4.15) we identified the contribution to the external stiffness matrix from mooring line number, $n$, as: 


$$
C_{i j}^{E, n}=\left[\begin{array}{c}
T_{k l}^{n} A_{l j}^{n} \\
R_{k m}^{n} T_{m l}^{n} A_{l j}^{n}
\end{array}\right]
$$

Where the subscript, $n$, refers to the attachment point number. This means that the matrices $R_{k l}, T_{k l}$, and $A_{l j}$ have to be found for each mooring line. Note that $T_{k l}^{n} A_{l j}^{n}$ is a $3 \times 6$ matrix in upper part of the stiffness matrix, $C_{i j}^{E, n}$, just as $R_{k m}^{n} T_{m l}^{n} A_{k j}^{n}$ is a $3 \times 6$ matrix in the lower part. Finally, the total external contribution to the restoring matrix was found as the sum of all the contributions:

$$
C_{i j}^{E}=\sum_{n=1}^{n_{\max }} C_{i j}^{E, n}
$$

To find the forces and derivatives of the forces at an attachment point from the mooring lines, eqs. (4.10) and (4.11), we used the following expressions for the horizontal and vertical forces. The expressions can be found in the literature, for instance in (Faltinsen, 1990). The horizontal force, $T_{H}$ , in the line is:

$$
T_{H}=\frac{w \cdot h}{\cosh \left(\frac{X-l+\sqrt{h^{2}+2 a h}}{a}\right)-1}
$$

The vertical force, $T_{V}$, is:

In order to describe the derivatives of the horizontal and vertical forces we described the total horizontal length, $X$, (i.e. the projection of $l$ on a horizontal seabed) as:

$$
X=l-h\left(1+2 \frac{a}{h}\right)^{1 / 2}+a \cosh ^{-1}\left(1+\frac{h}{a}\right)
$$

Where $w$ is the submerged weight of the mooring line per unit length, $h$ is the vertical distance from seabed to attachment point, $l$ the total length of the mooring line, $X$ the total horizontal length of mooring line (i.e. the projection of $l$ on a horizontal seabed), and a is, $a=T_{H} / w$.

The derivatives can be found numerically or analytically. Analytical formulations were used in this study and the expressions were tested numerically for their validity.

The derivative of $T_{H}$ with respect to $X$ can also be found in (Faltinsen, 1990): 


$$
\frac{d T_{H}}{d X}=\frac{w}{\cosh ^{-1}\left(\frac{h}{a}+1\right)-\frac{2}{\sqrt{\frac{2 a}{h}+1}}}
$$

In the design of mooring systems, the main concern is to keep the position of a floating body (here floating breakwater) near an average position. However, the structure is allowed to move from wave to wave, which means that the mooring system is targeting the mean drift forces that are typically significantly smaller than the wave forces induced by the individual waves. In this context, eq. (4.21) plays a vital role in analysing mooring systems. In our case this was not expected to be sufficient, and a complete set-up of the external stiffness matrix was needed as expressed in eqs. (4.16) and (4.17). Therefore, the derivatives, $\frac{d T_{H}}{d z}, \frac{d T_{V}}{d X}$, and $\frac{d T_{V}}{d z}$ were also found. The derivative of $T_{H}$ with respect to the vertical coordinate $\mathrm{z}$ can be found to:

$$
\frac{d T_{H}}{d z}=\left(\frac{a w\left(a l_{s}\left(\cosh \left(\frac{x}{a}\right)-1\right)-h \sinh \left(\frac{x}{a}\right)(a+h)\right)}{a^{2} l_{s}\left(\cosh \left(\frac{x}{a}\right)-1\right)^{2}-h \sinh \left(\frac{x}{a}\right)\left(h^{2}+a h+l_{s}(X-l)\right)}\right)
$$

The derivative of $T_{V}$ with respect to $\mathrm{X}$ can be found to:

$$
\frac{d T_{V}}{d X}=\frac{\left[\sinh \left(\frac{x}{a}\right)-\frac{x}{a} \cosh \left(\frac{x}{a}\right)\right] \frac{d T_{H}}{d X}+w \cosh \left(\frac{x}{a}\right)}{1-\cosh \left(\frac{x}{a}\right)}
$$

The derivative of $T_{V}$ with respect to $z$ (or $h$ ) have been derived in a similar way as eqs. (4.21):

$$
\frac{d T_{V}}{d z}=w \sqrt{\frac{2 a}{h}+1}-\frac{T_{H}}{h \sqrt{\frac{2 a}{h}+1}}+\frac{1}{\sqrt{\frac{2 a}{h}+1}} \frac{d T_{H}}{d z}
$$

The Jacobian matrix, $T_{k l}$, as defined in eqs. (4.11) was found from eqs. (4.21), (4.22), (4.23), and (4.24). The horizontal direction was aligned with the sway motion while the vertical was aligned with the heave motion.

The first step was to find the horizontal force in the mooring lines. The sum of the four horizontal forces has to balance the mean drift force. When waves approach the FB from left to right we have: 


$$
F_{\text {meandrift }}=2 \cdot T_{H, \text { Left }}-2 \cdot T_{H, \text { Right }}
$$

612 An iterative procedure solved eqs. (4.25) applying eqs. (4.18). With known mean forces at the 613 attachment points the derivatives in eqs (4.11) can be found, and finally the external stiffness matrix 614 given by eqs. (4.17).

615

\subsubsection{External Stiffness matrix for the three cross-sections}

617 The estimation of the stiffness matrices followed the procedure presented above. The 618 submerged weight of the mooring line $w=0.589 \mathrm{~N} / \mathrm{m}$. The pretension in the mooring lines for 619 calm water was $T_{\text {pre }}=0.05 \mathrm{~N}$, the total line length $l=2.43 \mathrm{~m}$, and the active line length $l_{s}=0.3 \mathrm{~m}$.

620 The total horizontal extent was $X=2.29 \mathrm{~m}$ and the active part was $X=0.17 \mathrm{~m}$. When a cross-section 621 interacted with periodic waves, it was exposed to a mean drift force. This changed the position of 622 the cross-section and, therefore, also the force in the mooring lines. Eqs. (4.25) estimated the 623 horizontal forces in the mooring lines for a range of frequencies to account for the mean drift force. 624 Figure 20 shows the mean drift forces that were estimated with the numerical model with a length 625 of $70 \mathrm{~m}$. The length in the x-direction (surge) was significantly larger in the numerical analyses than 626 in the experiments in order to reduce the influence of 3D effects at the ends. Then the mean drift 627 force was multiplied with a factor $0.58 / 70=8.29 \cdot 10^{-3}$ for the three cross-sections to resemble the 628 laboratory length of cross-section of the FB. The wave height was set to the equivalent deep water 629 steepness of $2 \%$, as described in subsection 2.2.2. 
632

633

634

635

636

637

638

639

640

641

642

643

644

645

646

647

648

649

650

651

652

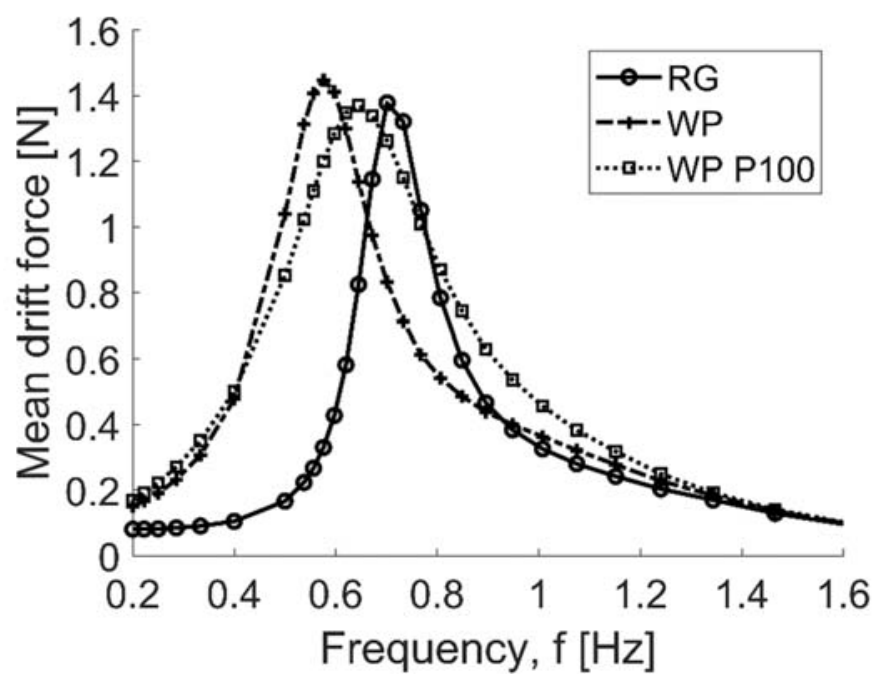

Figure 20 Calculated mean drift forces for cross-sections with a length of the FB corresponding to the physical experiments.

The only remaining quantities that were needed to find the external restoring coefficients were the distance vectors from the local body coordinate system to the attachment points of the mooring cables. The first vector that is located in one corner in the $x-y-p l a n e$ is:

$$
r_{j}^{1}=(0.23 m, 0.17 m,-0.385 m)
$$

The remaining vectors were found in a similar way, located at the other three corners in the $x-y-$ plane. The z-coordinate was constant in all four positions.

\section{Comparison of experimental and numerical results}

To examine the performance of the FB, numerical analyses were carried out and compared to the experimental results. This will support the conclusions from the experiments and further show how much of the non-linear processes can be captured with a linear radiation/diffraction analysis. To improve the numerical analyses, rough estimates of the viscous damping in the porous media and vortex generation around the edges of the FB, were included.

Based on the estimated damping ratios the final numerical setup was achieved. The numerical model calculated the response amplitude operators for the three cross sections of the FB for the three degrees of freedom sway, heave and roll. Figure 21 shows all 9 response amplitude operators (RAO). For the regular FB (RG) we found a good consistency between the experiments and the 
653 numerical results for sway and heave. The roll motion was smaller in the experiments compared to 654 the numerical results. Roll damping is often a non-linear process that cannot be fully accounted for 655 with linear damping. Therefore, this discrepancy could be expected. For the cross section with wing 656 plates (WP) a good consistency was also found for sway and heave, while the roll was less well 657 reproduced in the numerical analyses. This was again seen as a result of the non-linear damping 658 process that was considered even more important in this case due to the attached wing plates. In the 659 third cross section with porous sides (WP P100) a reasonable agreement was achieved for sway and 660 heave, although the differences between the numerical results and the experimental results were 661 larger compared to the other two cross sections; (RG) and (WP). Again, it was for the roll motion 662 that the differences were largest.

663 
$\mathrm{RG}$

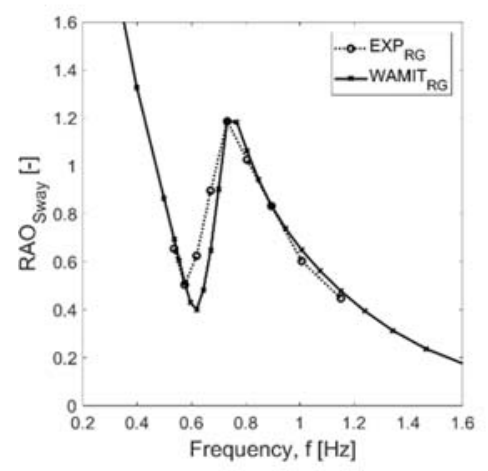

$\begin{array}{llllllll}0.038 & 0.080 & 0.132 & 0.202 & 0.298 & 0.425 & 0.577 & 0.753\end{array}$ $\mathrm{B}_{\mathrm{RO}} \mathrm{h}^{2}$

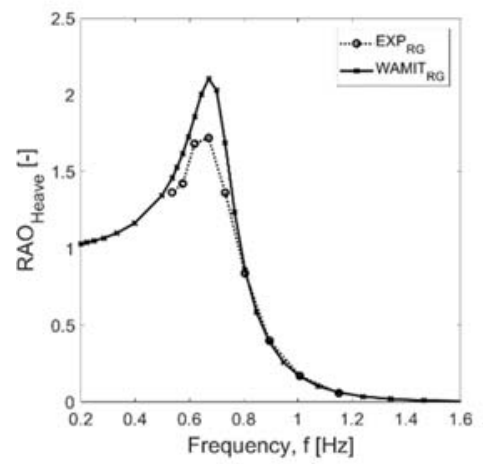

$\begin{array}{lllllllll}0.038 & 0.080 & 0.132 & 0.202 & 0.298 & 0.425 & 0.577 & 0.753\end{array}$ $\mathrm{B}_{\mathrm{RG}} \mathrm{R}^{\mathrm{L}}$

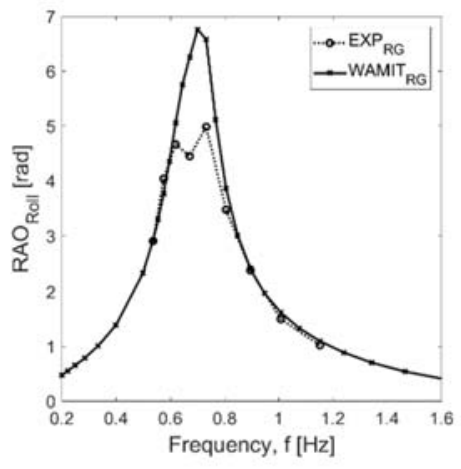

$\begin{array}{llllllllll}0.038 & 0.080 & 0.132 & 0.202 & 0.298 & 0.425 & 0.577 & 0.753\end{array}$
WP

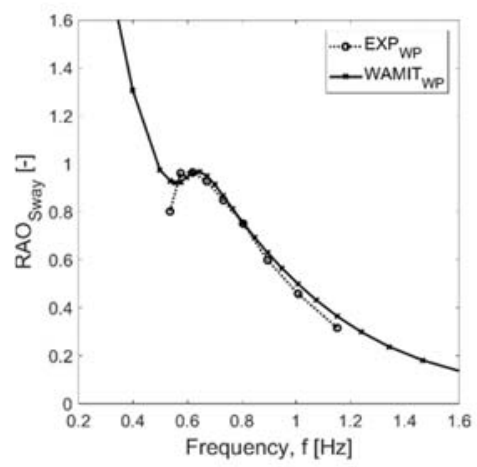

$\begin{array}{llllllll}0.038 & 0.080 & 0.132 & 0.202 & 0.298 & 0.425 & 0.577 & 0.753\end{array}$ $\mathrm{B}_{\mathrm{RO}} \mathrm{C}^{\mathrm{L}}$

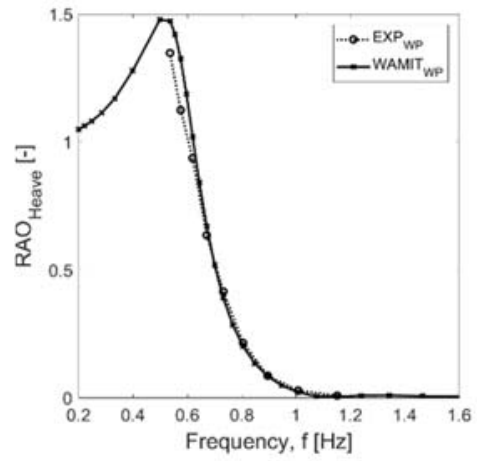

$\begin{array}{llllllll}0.038 & 0.080 & 0.132 & 0.202 & 0.298 & 0.425 & 0.577 & 0.753\end{array}$ $B_{R G^{\prime 2}}$

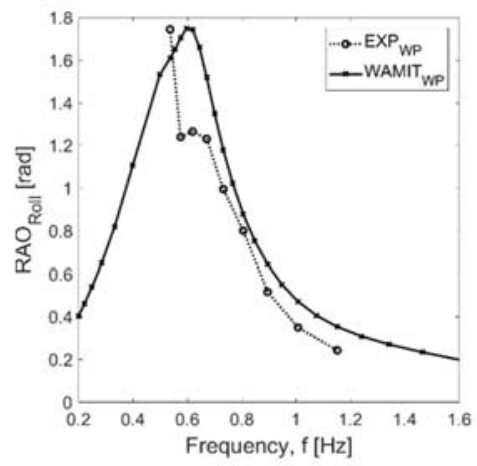

$\begin{array}{llllllll}0.038 & 0.080 & 0.132 & 0.202 & 0.298 & 0.425 & 0.577 & 0.753\end{array}$ $\mathrm{B}_{\mathrm{RG}}$
WP P100

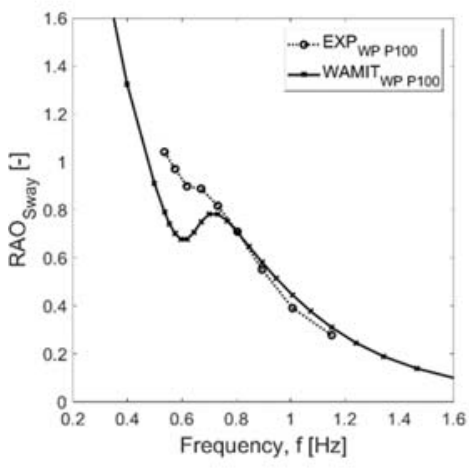

$\begin{array}{llllllll}0.038 & 0.080 & 0.132 & 0.202 & 0.298 & 0.425 & 0.577 & 0.753\end{array}$ $\mathrm{B}_{\mathrm{RO}} \mathrm{h}$

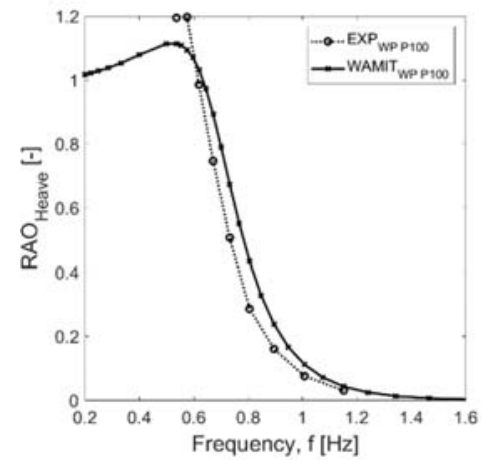

$\begin{array}{llllllll}0.038 & 0.080 & 0.132 & 0.202 & 0.298 & 0.425 & 0.577 & 0.753\end{array}$ $\mathrm{B}_{\mathrm{RG}} \mathrm{h}^{\mathrm{L}}$

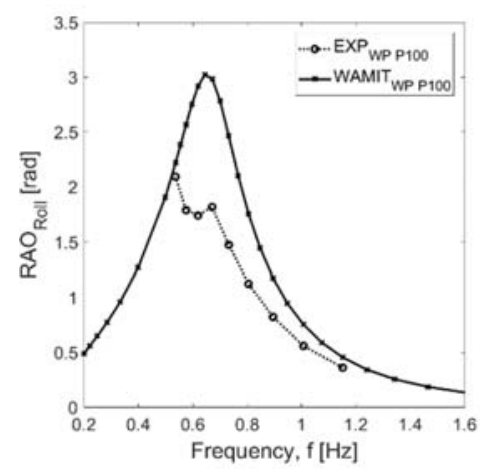

$\begin{array}{llllllll}0.038 & 0.080 & 0.132 & 0.202 & 0.298 & 0.425 & 0.577 & 0.753\end{array}$
665

666 667

668 669

Figure $21 \quad$ Comparison between Response Amplitude operators from experimental results and WAMIT calculations. simple equivalent linear damping. Besides the nonlinearity of the damping, this process can be 
670 argued to also change the effective mass and inertia of the structure. However, given the simplicity 671 of the modelling, the results shown in Figure 21 are encouraging.

672 Wave characteristics were extracted in front of the FB and on the lee-side of the FB in the 673 middle of the FB (along the y-axis), over a distance of $10 \mathrm{~m}$ on each side. This gave consistent 674 estimates of the wave amplitudes. As the incoming wave amplitude was known the reflected 675 amplitude was derived from the amplitude on the front, while the amplitude on the lee side was 676 assumed to be equal to the transmitted wave. Based on these wave amplitudes transmission and 677 reflection coefficients were determined with eqs. (2.2) and (2.3). Note that the computational model 678 size in the surge-direction (x-axis) was taken to be $70 \mathrm{~m}$ in order to minimise the 3D end effects.

679 This length was chosen after sensitivity tests that showed the results to independent of the length of 680 the structure. Even for a smaller length of the FB, as for instance $10 \mathrm{~m}$, the influence from the ends 681 was small. Figure 22, Figure 23, and Figure 24 compare the reflection and transmission coefficients 682 estimated from the experiments with the computed results. For the regular cross section (RG) we 683 found only a small difference between the results, but the reflection coefficient was slightly smaller 684 in the experiment compared to the numerical analyses. In the case with wing plates (WP) the 685 reflection coefficient, $\mathrm{C}_{\mathrm{R}}$, from the experiments was slightly smaller than the one found from 686 numerical analyses. The transmission coefficient, $\mathrm{C}_{\mathrm{T}}$, found from experiments and numerical 687 analyses was approximately the same.

688 For the two first cross sections, (RG) and (WP), we found a good agreement between the 689 experimental and numerical results, as outlined above. In the third cross section with attached 690 porous sides, (WP P100), this changed as illustrated in Figure 24. Here the reflection coefficient, $691 \mathrm{C}_{\mathrm{R}}$, was lower than 0.4 for all frequencies in the experiments while it continued to increase with 692 increasing wave frequency in the numerical analyses. The transmission coefficient was also highly 693 modified by the porous sides in the experiments, while the numerical results behave in much the 694 same way as for the other two cross sections. The external damping that was included in the 695 calculations resulted in a satisfactory agreement for the body response, but it clearly failed to 696 capture the reflection and transmission coefficients correctly. While the added viscous damping 697 removes energy from the motion response and, thus the waves radiated by the body motion, it has 698 no effect on the diffraction problem, i.e. the waves scattered by the fixed body. This presumably 699 explains the large errors at higher frequencies where diffraction effects become more and more 700 important. 


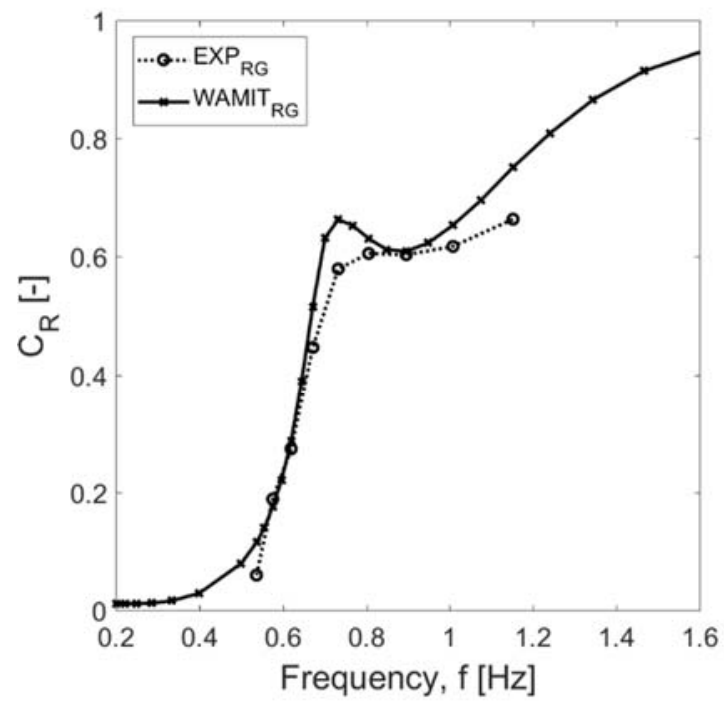

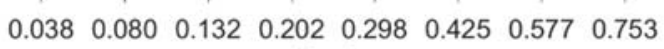
$\mathrm{B}_{\mathrm{RG}} / \mathrm{L}$

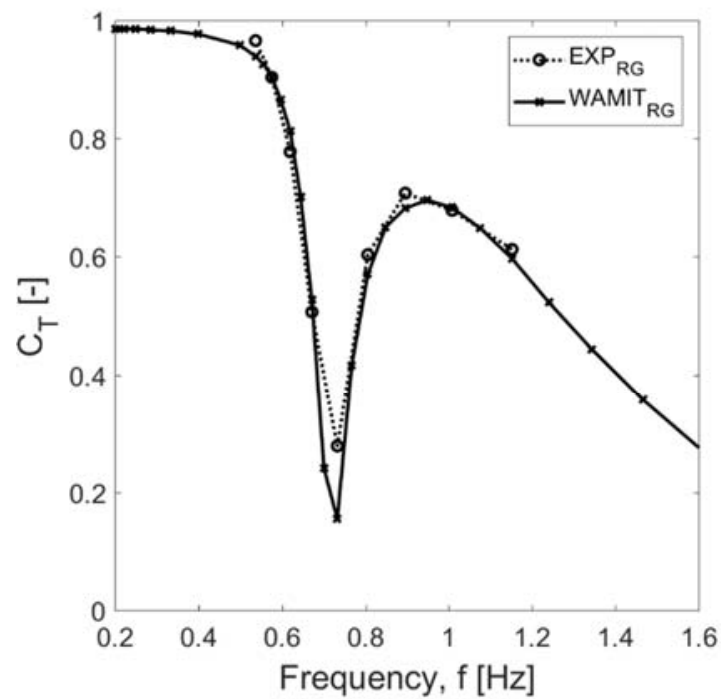

$\begin{array}{llllllll}0.038 & 0.080 & 0.132 & 0.202 & 0.298 & 0.425 & 0.577 & 0.753\end{array}$

$$
\mathrm{B}_{\mathrm{RG}} / \mathrm{L}
$$

702

703

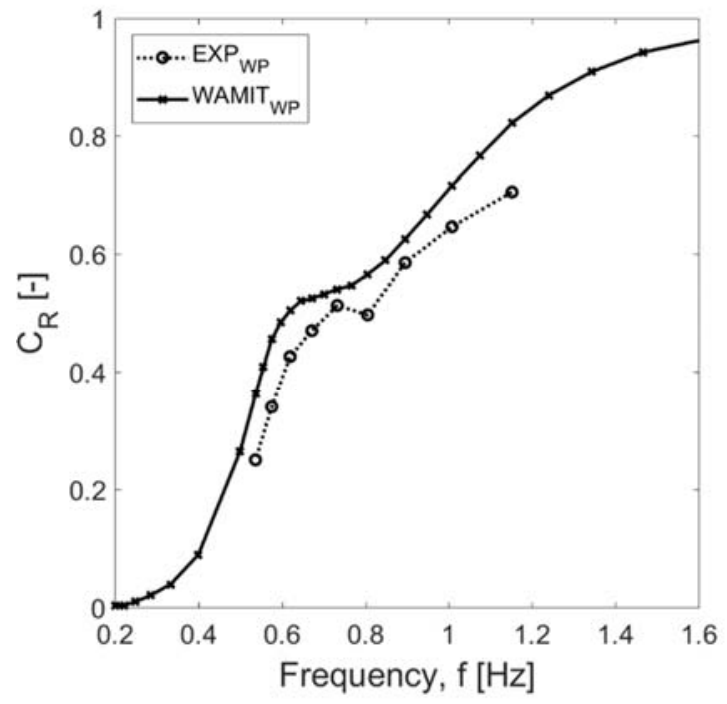

$\begin{array}{llllllll}0.038 & 0.080 & 0.132 & 0.202 & 0.298 & 0.425 & 0.577 & 0.753\end{array}$

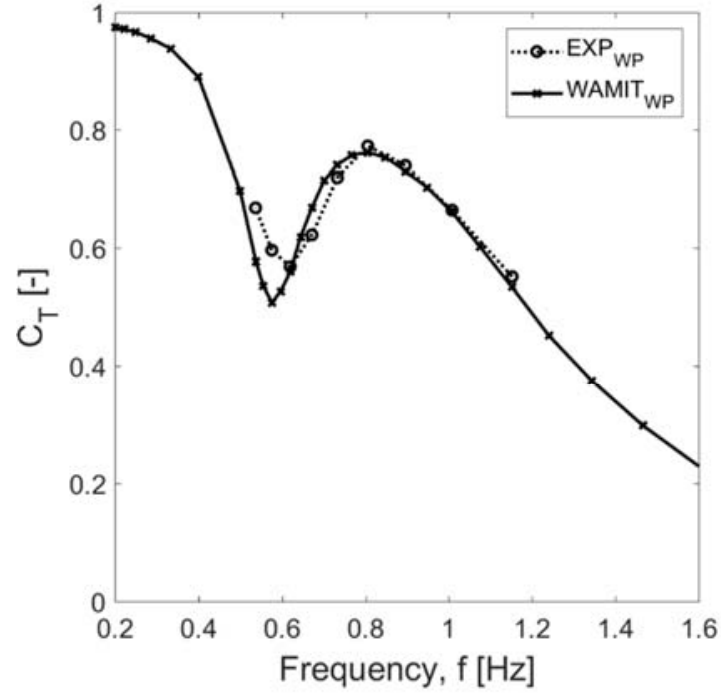

$\begin{array}{llllllll}0.038 & 0.080 & 0.132 & 0.202 & 0.298 & 0.425 & 0.577 & 0.753\end{array}$

$$
\mathrm{B}_{\mathrm{RG}} / \mathrm{L}
$$

704

705

706

707

708
Figure 23 Wings cross section (WP). Comparison of reflection and transmission coefficients between experimental results and numerical results based on WAMIT analyses. 


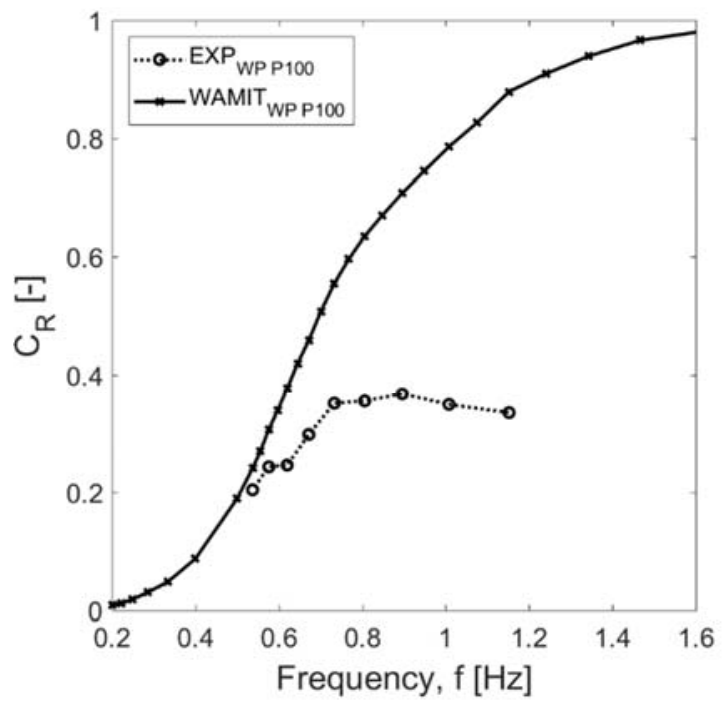

$\begin{array}{llllllll}0.038 & 0.080 & 0.132 & 0.202 & 0.298 & 0.425 & 0.577 & 0.753\end{array}$

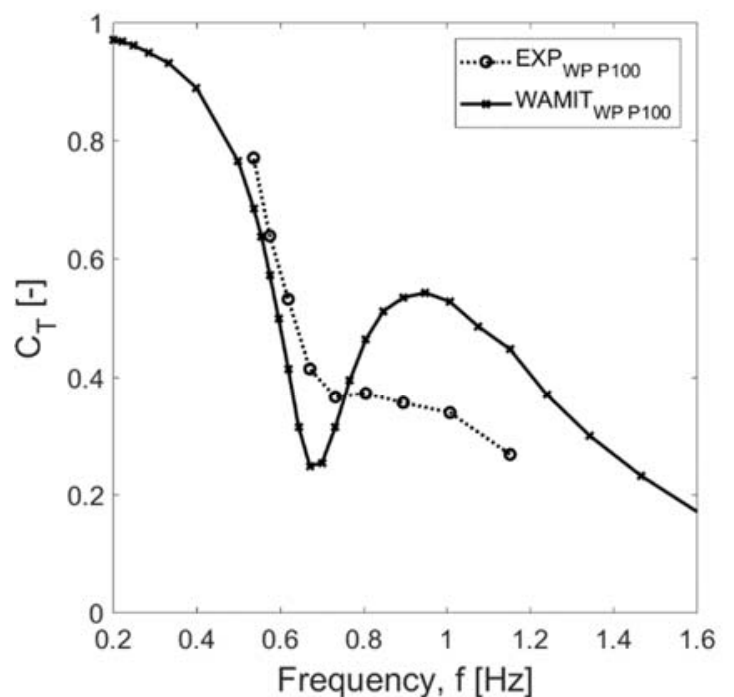

$\begin{array}{llllllll}0.038 & 0.080 & 0.132 & 0.202 & 0.298 & 0.425 & 0.577 & 0.753\end{array}$ $\mathrm{B}_{\mathrm{RG}}{ }^{\prime} \mathrm{L}$

\section{Figure 24}

coefficients between experimental results and numerical results based on WAMIT analyses.

\section{Conclusions}

Two different damping mechanisms for a FB were studied experimentally and numerically.

The basis for the analysis was a regular box shaped breakwater (RG). The first damping mechanism was attached wing plates (WP), and the second, wing plates with a porous media (WP P100) attached to the vertical sides of the FB. The experiments were carried out in one of DTU's wave flumes. The motion of the FB was measured with two different systems; Particle Tracking (PT) and Accelerometers (ACC). The particle tracking system worked well for all the three investigated degrees of freedom, sway, heave and roll. The accelerometers worked well for the heave and roll motions. The difference between the two methods was up to around 2-5\%.

Comparison of the response amplitude operators (RAO) between the three cross sections showed the (RG)-cross section had the largest response to the waves. For the sway motion the (WP P100)-cross section damped the motion most significantly, while for the other two degrees of freedom, heave and roll, it was the (WP)-cross section that damped the motion to the largest extent. Both cross sections with damping mechanisms reduced the motion by factors of 0.5 to 0.8 .

As the objective of breakwaters is to reduce the wave agitation on the lee side of the structure, the reflection and transmission coefficients were estimated from the experiments. The reflection 
coefficient had approximately the same dependency on the wave frequency for the (RG)-cross section and the (WP) cross section. Further, the reflection coefficient increased with increasing wave frequency. The (WP P100) cross section reduced the reflection coefficient with an increasing effect with increasing wave frequency. The largest reduction in the reflection coefficient was found for the largest examined wave frequency. For wave frequencies lager than $0.9 \mathrm{~Hz}$, the two cross sections (RG) and (WP) had a transmission coefficient in the order of 0.6 to 0.8 that decreased with increasing wave frequency. The cross section with wing plates and porous media (WP P100) had a transmission coefficient in the order of 0.3 to 0.4 for the larger wave frequencies, and with a decreasing tendency with increasing wave frequency. These analyses showed the cross section with porous media attached to the sides could significantly reduce the reflection and transmission coefficients. The effect was also studied from an energy point of view, where the effect obviously was enhanced. More than $80 \%$ of the incoming wave energy was dissipated with the cross section with porous sides (WP P100) for wave frequencies larger than 0.6 , while less than $20 \%$ for the other two cross sections, (RG) and (WP).

The motion, reflection and transmission coefficients were also examined with numerical analyses using WAMIT. As the frictional damping is not modelled directly, an additional analysis of the damping was carried out in the wave flume using decay tests. Based on these tests, an external damping matrix accounting for the viscous damping was included in the numerical analyses. Comparison between response amplitude operators found from experiments and numerical calculations showed in general a good agreement for sway and heave. In roll, the agreement was less good close to resonance, but better outside the area of resonance. For the cross section with porous sides (WP P100) the agreement was still fair for frequencies larger than $0.8 \mathrm{~Hz}$. For smaller frequencies, the comparison between measured response amplitude operators was in less good agreement. It was suggested that this might be related to filling and emptying the porous media, which cannot be modelled by a simple external damping coefficient. The modelled reflection and transmission coefficients for the regular cross section $(R G)$ and the cross section with wing plates (WP) agreed well with the coefficients estimated from the measurements. The cross section with porous sides (WP P100) showed significantly smaller reflection and transmission coefficients for wave frequencies larger than $0.8 \mathrm{~Hz}$ than those found by the numerical analysis. This difference was attributed to dissipation of the diffraction wave in the experiments, a process that cannot be modelled by a simple linear external damping coefficient. 


\section{References}

Abul-Azm, A.G., Gesraha, M.R., 2000. Approximation to the hydrodynamics of floating pontoons under oblique waves. Ocean Eng. 27, 365-384. doi:10.1016/S0029-8018(98)00057-2

Christensen, E.D., Stuiver, M., Guanche, R., Møhlenberg, F., Schouten, J.-J., Svenstrup Pedersen, O., He, W., Zanuttigh, B., Koundouri, P., 2015. Go offshore - Combining food and energy production. Technical University of Denmark. Department of Mechanical Engineering, Kgs. Lyngby, Denmark.

CIRIA, CUR, CETMEF, 2007. The Rock Manual. The use of rock in hydraulic engineering, 2nd ed. C683, CIRIA, London.

Dong, G.H., Zheng, Y.N., Li, Y.C., Teng, B., Guan, C.T., Lin, D.F., 2008. Experiments on wave transmission coefficients of floating breakwaters. Ocean Eng. 35, 931-938. doi:10.1016/j.oceaneng.2008.01.010

Drimer, N., Agnon, Y., Stiassnie, M., 1992. A simplified analytical model for a floating breakwater in water of finite depth. Appl. Ocean Res. 14, 33-41. doi:10.1016/0141-1187(92)90005-5

Faltinsen, O.M., 1990. Sea Loads on Ships and Offshore structures. Cambridge University Press, UK.

Fenton, J., 1990. Nonlinear wave theories, in: Mehaute, B. Le, Hanes, D.M. (Eds.), The Sea, Vol. 9. Ocean Engineering Science. John Wiley \& Sons, Inc., New York, pp. 3-25.

Friis, A.P.S., Larsen, A.K., 2015. Analysis of floating breakwaters. Technical University of Denmark.

Garcia, N., Lara, J.L., Losada, I.J., 2004. 2-D numerical analysis of near-field flow at low-crested permeable breakwaters. Coast. Eng. 51, 991-1020. doi:10.1016/j.coastaleng.2004.07.017

Gesraha, M.R., 2006. Analysis of shaped floating breakwater in oblique waves: I. Impervious rigid wave boards. Appl. Ocean Res. 28, 327-338. doi:10.1016/j.apor.2007.01.002

Goda, Y., 2010. Random Seas and Design of Maritime Structures, 3rd Editio. ed. World Scientific Publishing Co. Pte. Ltd.

Hirt, C.., Nichols, B.., 1981. Volume of fluid (VOF) method for the dynamics of free boundaries. J. Comput. Phys. 39, 201-225.

Jacobsen, N.G., Fuhrman, D.R., Fredsøe, J., 2012. A wave generation toolbox for the open-source CFD library : OpenFoamr. Int. J. Numer. Methods fluids 70, 1073-1088. doi:10.1002/fld

Jacobsen, N.G., van Gent, M.R.A., Wolters, G., 2015. Numerical analysis of the interaction of irregular waves with two dimensional permeable coastal structures. Coast. Eng. 102, 13-29. 
doi:10.1016/j.coastaleng.2015.05.004

Jensen, B., Jacobsen, N.G., Christensen, E.D., 2014. Investigations on the porous media equations and resistance coefficients for coastal structures. Coast. Eng. 84, 56-72. doi:10.1016/j.coastaleng.2013.11.004

Ji, C.-Y., Chen, X., Cui, J., Gaidai, O., Incecik, A., 2016. Experimental study on configuration optimization of floating breakwaters. Ocean Eng. 117, 302-310. doi:10.1016/j.oceaneng.2016.03.002

Ji, C.Y., Chen, X., Cui, J., Yuan, Z.M., Incecik, A., 2015. Experimental study of a new type of floating breakwater. Ocean Eng. 105, 295-303. doi:10.1016/j.oceaneng.2015.06.046

Koutandos, E. V., Karambas, T. V., Koutitas, C.G., 2004. Floating Breakwater Response to Waves Action Using a Boussinesq Model Coupled with a 2DV Elliptic Solver. J. Waterw. Port, Coastal, Ocean Eng. 130, 243-255. doi:10.1061/(ASCE)0733-950X(2004)130:5(243)

Lee, C.-H., Newman, J.N., 2003. Computation of wave effects using the panel method, in: Numerical Models in Fluid Structure Interaction, Preprint. pp. 1-41.

Losada, I.J., Lara, J.L., Christensen, E.D., Garcia, N., 2005. Modelling of velocity and turbulence fields around and within low-crested rubble-mound breakwaters. Coast. Eng. 52, 887-913. doi:10.1016/j.coastaleng.2005.09.008

Loukogeorgaki, E., Yagci, O., Sedat Kabdasli, M., 2014. 3D Experimental investigation of the structural response and the effectiveness of a moored floating breakwater with flexibly connected modules. Coast. Eng. 91, 164-180. doi:10.1016/j.coastaleng.2014.05.008

Loukogeorgaki, E., Angelides, D.C., 2005. Stiffness of mooring lines and performance of floating breakwater in three dimensions. Appl. Ocean Res. 27, 187-208. doi:10.1016/j.apor.2005.12.002

Newman, J.N., 1977. Marine Hydrodynamics. The MIT Press, Cambrigde, London.

Pastor, J.M., 2007. Software for Particle Tracking, Version 1.0.

Perez, T., Blanke, M., 2012. Ship roll damping control. Annu. Rev. Control 36, 129-147. doi:10.1016/j.arcontrol.2012.03.010

Rahman, M.A., Mizutani, N., Kawasaki, K., 2006. Numerical modeling of dynamic responses and mooring forces of submerged floating breakwater. Coast. Eng. 53, 799-815. doi:10.1016/j.coastaleng.2006.04.001

Sannasiraj, S.A., Sundar, V., Sundaravadivelu, R., 1998. Mooring forces and motion responses of pontoon-type floating breakwaters. Ocean Eng. 25, 27-48. doi:10.1016/S0029- 
Sumer, B.M., Fredsøe, J., 2006. Hydrodynamics Around Cylindrical Structures (Revised Edition), Advanced Series on Ocean Engineering. World Scientific Publishing Co. Pte. Ltd., New Jersey. London, Singapore, Beijing, Shanhai, Hong Kong, Taipei, Chennai.

828 doi:10.1142/9789812772770

829

Tang, H.-J., Huang, C.-C., Chen, W.-M., 2011. Dynamics of dual pontoon floating structure for

830

831 cage aquaculture in a two-dimensional numerical wave tank. J. Fluids Struct. 27, 918-936.

832 WAMIT Inc., 2015. WAMIT User Manual - Version 7.1. doi:10.1016/j.jfluidstructs.2011.06.009

833 Wang, H.Y., Sun, Z.C., 2010. Experimental study of a porous floating breakwater. Ocean Eng. 37 , 834 520-527. doi:10.1016/j.oceaneng.2009.12.005

835 Williams, J.M., 1981. Limiting gravity waves of finute depth. Philos. Trans. R. Soc. London. Ser. 836 A, Math. Phys. Eng. Sci. 302, 139-188.

837

838 
839 Figure 1 Definition sketch of the DOF (Degrees Of Freedom) that was examined in this study....4

840 Figure 2 Sketch of the wave flume. The sketch is divided into sections to keep proportions..............5

841 Figure 3 Positions of wave gauges in unit [mm] ........................................................................... 6

842 Figure 4 Schematic top-view of the flume with black curtain set-up................................................ 8

843 Figure 5 Positions of 4 white points on the side of the floating breakwater (FB) model: A, B, C, and

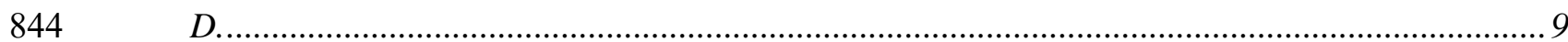

845 Figure 6 Sketch of the set-up of the accelerometers for the FB model with wings. The vertical

$846 \quad$ distance from the MWL to the lid is indicated on the right panel........................................... 10

847 Figure $7 \quad$ Basic cross section of the regular pontoon $(R G)$ floating breakwater..........................11

848 Figure 8 The basic three different types of breakwaters, (RG), (WP), and (WP P100)..................11

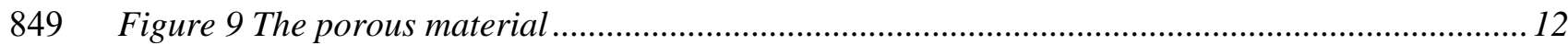

850 Figure 10 Response amplitude operator (RAO) for Sway derived from experiments for three

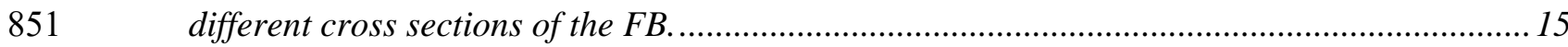

852 Figure 11 Response Amplitude Operators (RAO) Heave derived from experiments for three

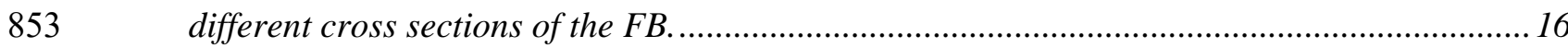

854 Figure 12 Response Amplitude Operators (RAO) Roll derived from experiments for three different

$855 \quad$ cross sections of the FB. 17

856 Figure 13 Reflection coefficient, $C_{R}$, for three different cross sections of the FB.....................18

857 Figure 14 Transmission coefficient, $C_{T}$, for three different cross sections of the FB..................19

858 Figure 15 Relative reflection of energy, $E_{R} / E_{\text {in }}$, for three different cross sections of the FB.....20

859 Figure 16 Relative transmission of energy, $E_{T} / E_{i n}$, for three different cross sections of the FB.

$860 \quad 21$

861 Figure 17 Relative dissipation of energy, $E_{D i s s} / E_{i n}$, for three different cross sections of the FB.

$862 \quad 22$

863 Figure 18 Decay tests for regular and pontoon with wings for sway, roll and heave. 24

864 Figure 19 Decay tests for regular and pontoon with wings and porous sides for sway, roll and 865 heave. 25

866 Figure 20 Calculated mean drift forces for cross-sections with a length of the FB corresponding to 867 the physical experiments. .35

868 Figure 21 Comparison between Response Amplitude operators from experimental results and 869 WAMIT calculations. 
870 Figure 22 Regular cross section (RG). Comparison of reflection and transmission coefficients

871 between experimental results and numerical results based on WAMIT analyses. .

872 Figure 23 Wings cross section (WP). Comparison of reflection and transmission coefficients

873 between experimental results and numerical results based on WAMIT analyses. ....................39

874 Figure 24 Wings with porous sides (WP P100). Comparison of reflection and transmission

875 coefficients between experimental results and numerical results based on WAMIT analyses. .40

876 